\title{
Size Dependence of the Drying Characteristics of Single Lignite Particles in Superheated Steam
}

\author{
TSUYOSHI KIRIYAMA, HIDEAKI SASAKI, AKIRA HASHIMOTO, SHOZO KANEKO, \\ and MASAFUMI MAEDA
}

\begin{abstract}
Loy Yang lignite particles 10,5 , and $2.5 \mathrm{~mm}$ in diameter were dried with superheated steam at temperatures ranging from $383 \mathrm{~K}$ to $443 \mathrm{~K}\left(110{ }^{\circ} \mathrm{C}\right.$ to $\left.170{ }^{\circ} \mathrm{C}\right)$ under atmospheric pressure. The drying rates were obtained by measuring their weights with an electronic balance, while temperatures of the particles were monitored. The following typical drying characteristics were observed: (i) Temperature of lignite rose to $373 \mathrm{~K}\left(100^{\circ} \mathrm{C}\right)$ accompanied by condensation of steam on the surface. (ii) A constant drying rate period was then observed, while temperature of the overall particle was maintained at $373 \mathrm{~K}\left(100^{\circ} \mathrm{C}\right)$. (iii) A decreasing drying rate period began accompanied by a rise in surface temperature, and eventually the overall particle reached the temperature of the superheated steam. Based on these results, the evaporation rate of water was expressed as a function of particle diameter. A numerical model for simulating the drying process of lignite, which was developed for a large particle in a previous study, was modified to make it applicable to small particles. The model is applicable for simulations of drying behaviors of lignite with size distribution in various dryers when an appropriate heat transfer coefficient is given.
\end{abstract}

DOI: $10.1007 / \mathrm{s} 40553-014-0037-2$

(C) ASM International (ASM) and The Minerals, Metals, \& Materials Society (TMS) 2014

\section{INTRODUCTION}

LIGNITE, or brown coal, is the lowest rank of coal, and accounts for 23 pct of the proven recoverable reserves of all coal. ${ }^{[1]}$ Because of its high moisture content, which makes the cost of transporting the raw lignite high, it is mainly used as a fuel in thermal power stations located near source mines. In addition, dried lignite is difficult to transport and store because it has a propensity to combust spontaneously.

Since water vaporization causes heat loss in lignite-fired power stations, a drying system is necessary to improve thermal efficiency and reduce $\mathrm{CO}_{2}$ emissions. Drying with superheated steam is promising because it can prevent spontaneous combustion of lignite, and thermal efficiency can be improved with self-heat recuperation systems. A steam fluidized bed dryer (SFBD) on a commercial scale has been developed recently in Germany, ${ }^{[2]}$ and a pilot dryer using pressurized steam also has been constructed. ${ }^{[3]}$

While the drying characteristics of lignite in an air fluidized bed dryer have been studied, ${ }^{[4-7]}$ available information on steam fluidized bed drying is limited despite continuing dryer research and development. Additionally, the behavior of single lignite particles, which is fundamental to comprehending the drying processes, has been reported only for particles $10 \mathrm{~mm}$ or

TSUYOSHI KIRIYAMA, Cooperative Research Fellow, HIDEAKI SASAKI, Research Associate, AKIRA HASHIMOTO, SHOZO KANEKO, and MASAFUMI MAEDA, Professors, are with the Institute of Industrial Science, The University of Tokyo, 4-6-1 Komaba, Meguro-ku, Tokyo, 153-8505 Japan. Contact e-mail: kiriyama@iis.u-tokyo.ac.jp

Manuscript submitted January 12, 2014.

Article published online November 5, 2014 larger, ${ }^{[8,9]}$ although sizes are assumed to be less than $10 \mathrm{~mm}$ in an actual process.

To develop a greater understanding of steam fluidized bed drying, the authors previously examined steam drying of $30 \mathrm{~mm}$ single lignite particles, ${ }^{[10]}$ and a singleparticle model based on the experimental results was developed in order to simulate the drying of a coarse particle. The purpose of the present study was to examine the drying of smaller lignite particles in superheated steam using particles 10,5 , and $2.5 \mathrm{~mm}$ in diameter. The size dependence of their drying characteristics was determined, and the numerical model was improved to adapt it to a wider range of sizes.

\section{EXPERIMENTAL METHOD}

\section{A. Sample Preparation}

Loy Yang lignite from Victoria, Australia, with a moisture content of about 62 mass pet was cut into spherical samples with specialized tools. Initial diameters of the samples, $D$, were 10,5 , and $2.5 \mathrm{~mm}$, and their average weights were $0.59,0.073$, and $0.009 \mathrm{~g}$, respectively. Figure 1 shows the samples and their setting schemes. A glass rod $0.5 \mathrm{~mm}$ in diameter was used to suspend the samples with $D=10$ and $5 \mathrm{~mm}$ under an electronic balance (Figures 1(a) and (b)), and a K-type thermocouple was used to measure the temperature at the sample center, $T_{\text {center }}$. The thermocouple was composed of insulated chromel and alumel wires $0.08 \mathrm{~mm}$ in diameter, and was set in $0.2-\mathrm{mm}$-diameter drilled holes. For samples with $D=10 \mathrm{~mm}$, another thermocouple was used to measure the temperature at the midpoint 


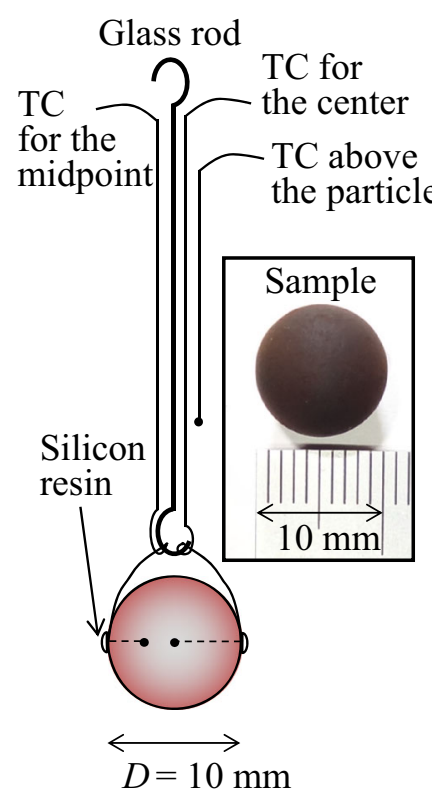

(a)

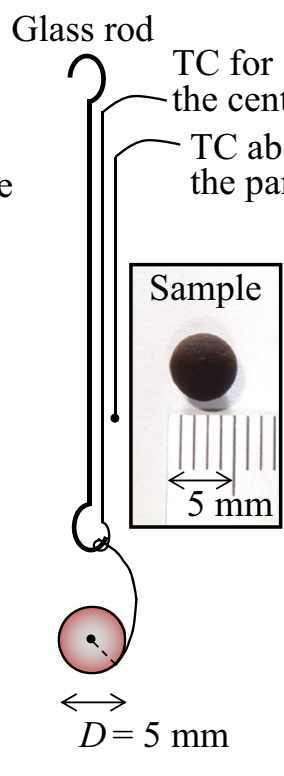

(b)

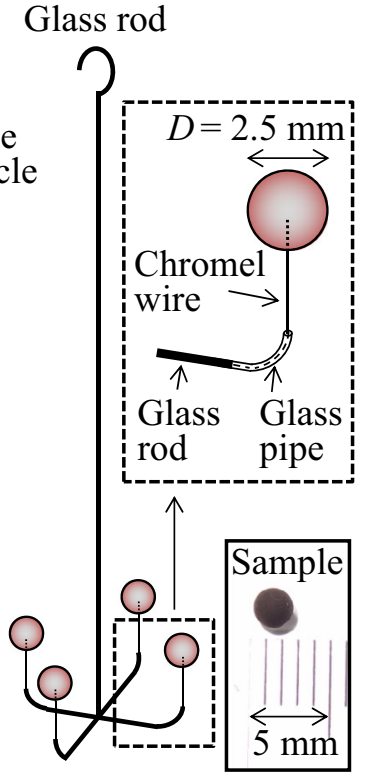

(c)

Fig. 1-Samples and their setting schemes. (a) 10, (b) 5, and (c) $2.5 \mathrm{~mm}$ in diameter. TC: Thermocouple.

between the center and the surface, $T_{\text {midpoint. }}$ For the $10 \mathrm{~mm}$ samples, a minuscule quantity of silicon resin was used to fix the positions of the thermocouples. To accurately observe the changes in weight of $2.5 \mathrm{~mm}$ samples, 4 particles were dried in a test as shown in Figure 1(c). They were supported by a branched glass rod $(0.6 \mathrm{~mm}$ in diameter $)$ which had curved pipes $(0.7 \mathrm{~mm}$ in outer diameter) on each end. Insulated $0.1-\mathrm{mm}$-diameter chromel wire was set in a drilled hole of each sample $0.1 \mathrm{~mm}$ in diameter and $1.0 \mathrm{~mm}$ in depth, and the other end of the wire was inserted in the pipe attached to the glass rod.

\section{B. Apparatus}

A schematic configuration of the experimental system is shown in Figure 2, where the sample was placed in a test section of $133 \mathrm{~mm}$ in diameter and 152-mm high. Temperature in the test section was controlled by electric heaters. Weight of the sample, $W$, was measured by an electronic balance having a resolution of $0.1 \mathrm{mg}$ (HR-200, A \& D Company). The sample could be isolated from the atmosphere in the test section by raising the starting pipe until the drying test was started.

Pure water was degassed and pumped up to an evaporator and a superheater. The superheated steam was sent into the top of the test section, to which a baffle plate was attached, and exhausted from the bottom using a fan. At the top of the test section, another small fan exhausted the leakage of superheated steam from an orifice, through which the glass rod suspending the sample had been passed. The glass rod was heated by a halogen lamp to prevent condensation of the steam on it. Air was supplied to an acryl pipe attached under the balance along the suspension wire at a rate of 1.0 $\left(\mathrm{dm}^{3} \min ^{-1}\right)\left(\mathrm{ANR}, 293 \mathrm{~K}\left(20^{\circ} \mathrm{C}\right), 101,325 \mathrm{~Pa}\right)$ to stabilize temperature and flow.

Temperatures inside samples ( $T_{\text {center }}$ and $\left.T_{\text {midpoint }}\right)$ were measured with the K-type thermocouples mentioned above. Surface temperature, $T_{\text {surface, }}$ was measured by a thermograph (R-300, NEC/Avio) having infrared bolometers capable of detecting wavelength from 8 to $12 \mu \mathrm{m}$. An optical path for the thermograph was located on the side of the test section, and a polymethylpentene film $10-\mu \mathrm{m}$ thick was set there as a window. The inside wall of the test section and the optical path were painted with a black body spray having an emissivity of 0.94 (THI-1B, Tasco Japan). Because lignite is maintained at $373 \mathrm{~K}\left(100{ }^{\circ} \mathrm{C}\right)$ during the early period of a drying process and then reaches the same temperature as surrounding superheated steam, the thermograph was calibrated on the basis of these two temperatures. The sample was observed with a video camera (HDR-CX170, Sony) through a glass window.

The area indicated by the dotted line in Figure 2 was enclosed with polyvinyl chloride sheets to prevent any fluctuations caused by air. The relative humidity in the enclosure was maintained at over 45 pct to eliminate the effect of static electricity.

\section{Procedure}

Considering the spontaneous combustion temperatures of Loy Yang lignite $\left[433 \mathrm{~K}\right.$ to $443 \mathrm{~K}\left(160{ }^{\circ} \mathrm{C}\right.$ to $\left.\left.170{ }^{\circ} \mathrm{C}\right)\right],{ }^{[11]}$ the samples were dried by superheated steam at $383 \mathrm{~K}, 403 \mathrm{~K}, 423 \mathrm{~K}$, and $443 \mathrm{~K}\left(110^{\circ} \mathrm{C}\right.$, $130{ }^{\circ} \mathrm{C}, 150{ }^{\circ} \mathrm{C}$, and $170{ }^{\circ} \mathrm{C}$, hereafter referred to as test temperature, $T_{\mathrm{a}}$ ). Before setting the sample, a test section was heated to $T_{\mathrm{a}}$ under a flow of nitrogen, then 


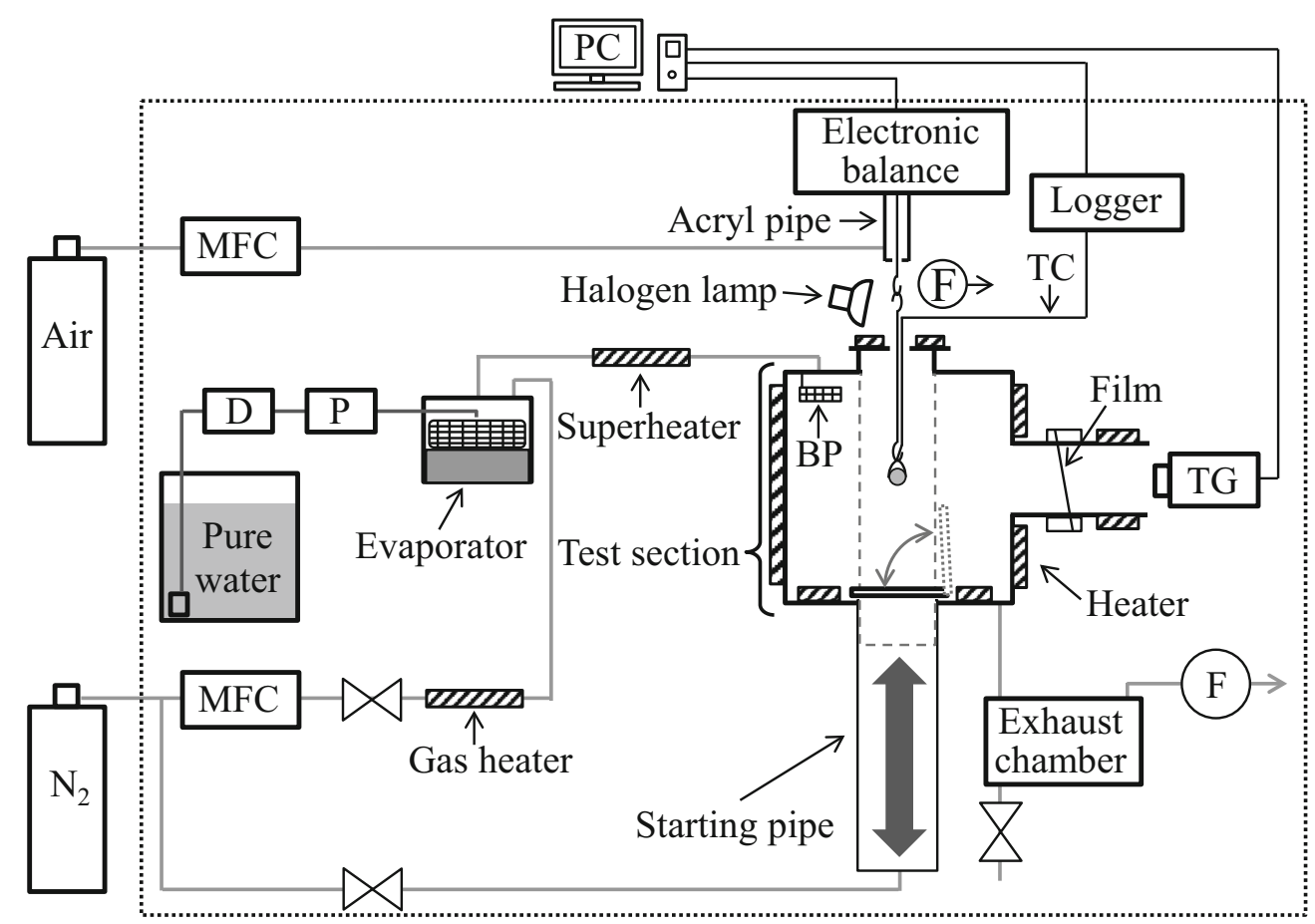

Enclosure of polyvinyl chloride sheets

Fig. 2-Schematic configuration of experimental system. MFC: Mass flow controller, D: degasser, P: feed pump, BP: baffle plate, TC: thermocouples, TG: thermograph, F: exhaust fan.

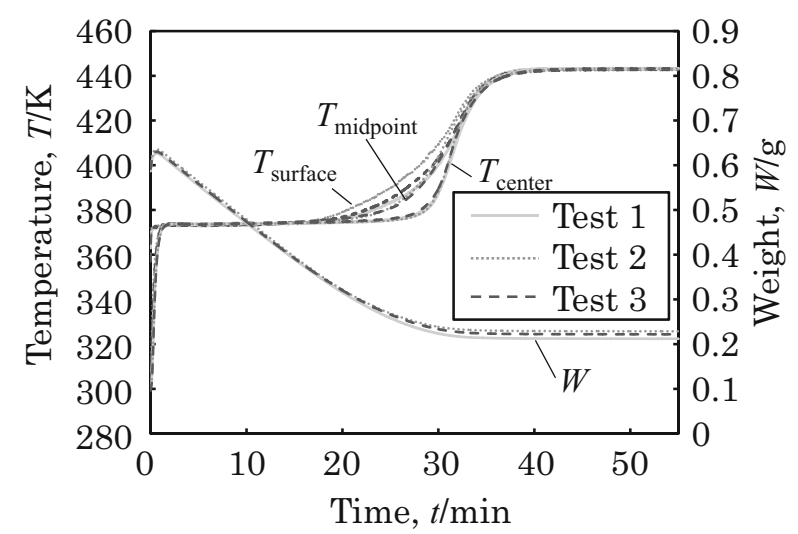

Fig. 3-Temperatures and weights of the samples $10 \mathrm{~mm}$ in diameter at a test temperature of $443 \mathrm{~K}\left(170^{\circ} \mathrm{C}\right)$.

the fluid was replaced with superheated steam. The test section was presumed to be filled with superheated steam under atmospheric pressure. The feed rate of water to the evaporator was $8 \mathrm{~cm}^{3} / \mathrm{min}$. Calculated from cross-sectional area, the average velocity of superheated steam was about $0.02 \mathrm{~m} / \mathrm{s}$ in the test section. The Reynolds numbers in this condition were about 6,3 , and 2 for $D=10,5$, and $2.5 \mathrm{~mm}$, respectively, which enabled accurate weighing of the sample in a laminar flow. After the test section was stabilized, the starting pipe was lifted to separate its internal space from the test section. The inside of the pipe was then purged with nitrogen, and the sample was hung under the electronic balance. From the time the pipe was lowered again, the sample was exposed to superheated steam and measurements were started. For samples with $D=10$ and $5 \mathrm{~mm}$, the start of drying was also monitored by a thermocouple placed above them (Figures 1(a) and (b)). $W$ and $T$ were recorded every 1 second. Drying was judged to have been completed when the change in $W$ became less than $0.1 \mathrm{mg} \mathrm{min}^{-1}$. Subsequently, the fluid was switched to nitrogen in order to evaporate residual water in the sample. $W$ after the nitrogen drying was regarded as the weight of coal contained in the lignite (dry coal), $W_{\mathrm{c}}$. The weight of water in the lignite, $W_{\mathrm{w}}$, was determined by subtracting $W_{\mathrm{c}}$ from the weight of the sample, $W$. The drying tests were conducted three times at each $T_{\mathrm{a}}$.

\section{EXPERIMENTAL RESULTS AND DISCUSSION}

\section{A. Changes in Temperature and Weight During Drying}

Figure 3 shows time variations of temperatures ( $T_{\text {surface }}, T_{\text {midpoint }}$, and $T_{\text {center }}$ ) and the weight of samples $(W)$ during three drying tests under identical conditions $\left(D=10 \mathrm{~mm}\right.$ and $\left.T_{\mathrm{a}}=373 \mathrm{~K}\left(170{ }^{\circ} \mathrm{C}\right)\right)$. Results from the three tests were similar, confirming reproducibility of the measurements. Experiments under other conditions also provided reproducible results, and thus representative data are shown hereafter.

Figure 4 shows results with samples of (a) 10, (b) 5, and (c) $2.5 \mathrm{~mm}$ at various temperatures. The appearance of the samples dried at $T_{\mathrm{a}}=443 \mathrm{~K}\left(170^{\circ} \mathrm{C}\right)$ is shown in Figure 5, where moisture content, $X$, is indicated. The 


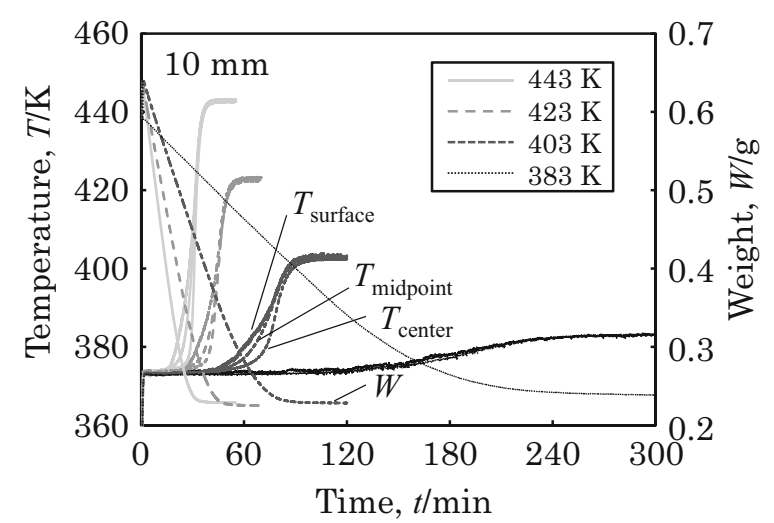

(a)

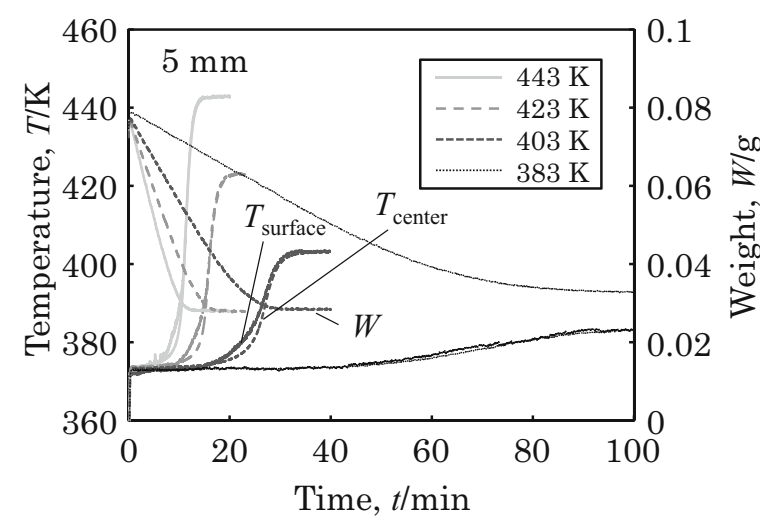

(b)

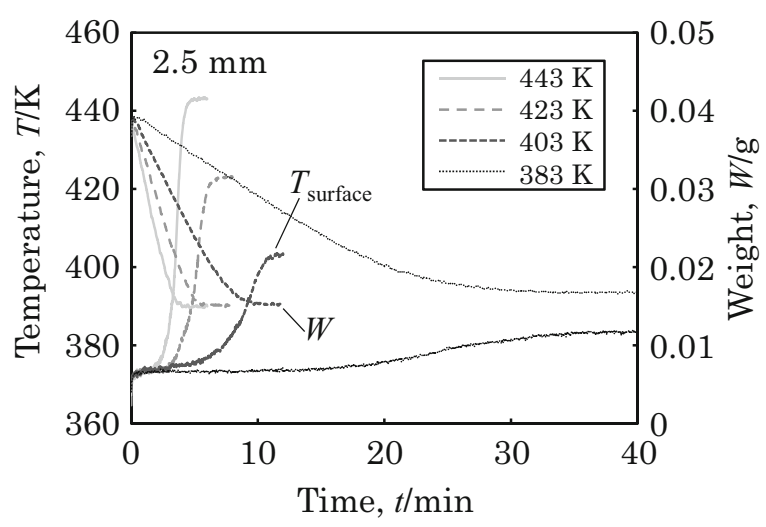

(c)

Fig. 4-Temperatures and weights of the samples (a) $10 \mathrm{~mm},(b)$ $5 \mathrm{~mm}$, and (c) $2.5 \mathrm{~mm}$ in diameter during entire drying process.

moisture content was defined as the weight of water divided by that of dry coal $\left(X=W_{\mathrm{w}} / W_{\mathrm{c}}\right)$, and its initial value $\left(X_{\text {ini }}\right)$ is shown in Table $\mathrm{I}$ (size dependence of $X$ is discussed later in Section III-B.).

Initially, drop-wise condensation of steam occurred on the surface (Figure 5). Figure 6 shows magnified views of Figure 4 at the initial stage, where $W$ temporarily increased. Meanwhile, the surface and inside of the samples reached $373 \mathrm{~K}\left(100{ }^{\circ} \mathrm{C}\right)$ in that order, as shown in Figures 6(a) and (b). Presumably, temperatures of lignite were increased in this stage mainly by the heat of condensation of the superheated steam. As shown in our previous study, ${ }^{[10]}$ the condensed water on the surface was removed by external force as a droplet under certain conditions. In this study, the falling of a water droplet was caught by video camera at $T_{\mathrm{a}}=383 \mathrm{~K}\left(110^{\circ} \mathrm{C}\right)$ after a lapse of 0.5 to 1.0 minutes in the drying of $10 \mathrm{~mm}$ particles. This loss of moisture corresponds to the sudden drop in $W$ in Figure 6(a), and looks significantly different from that in the previous study of $30 \mathrm{~mm}$ particles, where falling droplets were observed more than 10 times. ${ }^{[10]}$ Because the overall lignite particle was heated to $373 \mathrm{~K}\left(100{ }^{\circ} \mathrm{C}\right)$ by the condensation of steam in this period, more water condensed on larger particles, resulting in droplets falling at higher frequency. Additionally, the droplet fell only at $T_{\mathrm{a}}=383 \mathrm{~K}\left(110^{\circ} \mathrm{C}\right)$ in Figure 6(a), suggesting an influence from $T_{\mathrm{a}}$; also shown is that the initial increases in $W$ are greater for lower $T_{\mathrm{a}}$. The temperature dependency is explained by convective and radiant heat transfer, which is larger at higher $T_{\mathrm{a}}$, resulting in a smaller amount of condensed water on the lignite particles.

Measurements of the samples with $D=5 \mathrm{~mm}$ confirmed that $T_{\text {center }}$ rose more slowly than $T_{\text {surface, }}$ and reached $373 \mathrm{~K}\left(100{ }^{\circ} \mathrm{C}\right.$ ) (Figure $\left.6(\mathrm{~b})\right)$. When $D=2.5 \mathrm{~mm}$, $T_{\text {surface }}$ immediately became constant, which was believed to be at $373 \mathrm{~K}\left(100^{\circ} \mathrm{C}\right)$ (Figure 6(c)). No falling droplets were observed for the samples with $D=5$ and $2.5 \mathrm{~mm}$.

During the initial period shown in Figure 6, time variations of the temperatures were independent of $T_{\mathrm{a}}$. The results indicate that the internal temperature of the lignite particles was increased by heat conduction from its surface maintained at $373 \mathrm{~K}\left(100{ }^{\circ} \mathrm{C}\right)$.

After $T_{\text {center }}$ reached $373 \mathrm{~K}\left(100{ }^{\circ} \mathrm{C}\right)$, typical drying characteristics in superheated steam ${ }^{[12]}$ were observed. The temperatures of lignite were maintained at $373 \mathrm{~K}$ $\left(100^{\circ} \mathrm{C}\right.$ ) for a period (Figure 4), where $W$ decreased constantly. Then, $T_{\text {surface, }} T_{\text {midpoint }}$, and $T_{\text {center }}$ began rising from $373 \mathrm{~K}\left(100{ }^{\circ} \mathrm{C}\right)$ in that order, and reached $T_{\mathrm{a}}$. The formation and widening of cracks on the surface are shown in Figure 5, where more cracks can be observed on larger particles. Although not shown here, the cracks were fewer at lower $T_{\mathrm{a}}$ as was the case for samples of $30 \mathrm{~mm} .^{[10]}$ The generated cracks were then closed as the drying proceeded due to shrinkage of the sample. The time to complete drying, $t_{\text {comp }}$, is shown in Table I.

\section{B. Moisture Content and Drying Rate}

Figure 7 shows average water percentages by weight, $W_{\mathrm{w}} /\left(W_{\mathrm{c}}+W_{\mathrm{w}}\right) \times 100$, in the lignite before and after drying with superheated steam. Initial water was 63 and 62 mass pct (moisture content: 1.71 and 1.63, respectively) in the samples of 10 and $5 \mathrm{~mm}$. Water percentage in the $2.5 \mathrm{~mm}$ samples was 60 mass pct (moisture content: 1.47), indicating a slight drying before measurements. All samples were placed in nitrogen of about $373 \mathrm{~K}\left(100{ }^{\circ} \mathrm{C}\right)$ for about 10 seconds before the exposure to superheated steam, and smaller samples are more likely to be affected by drying during this period. 

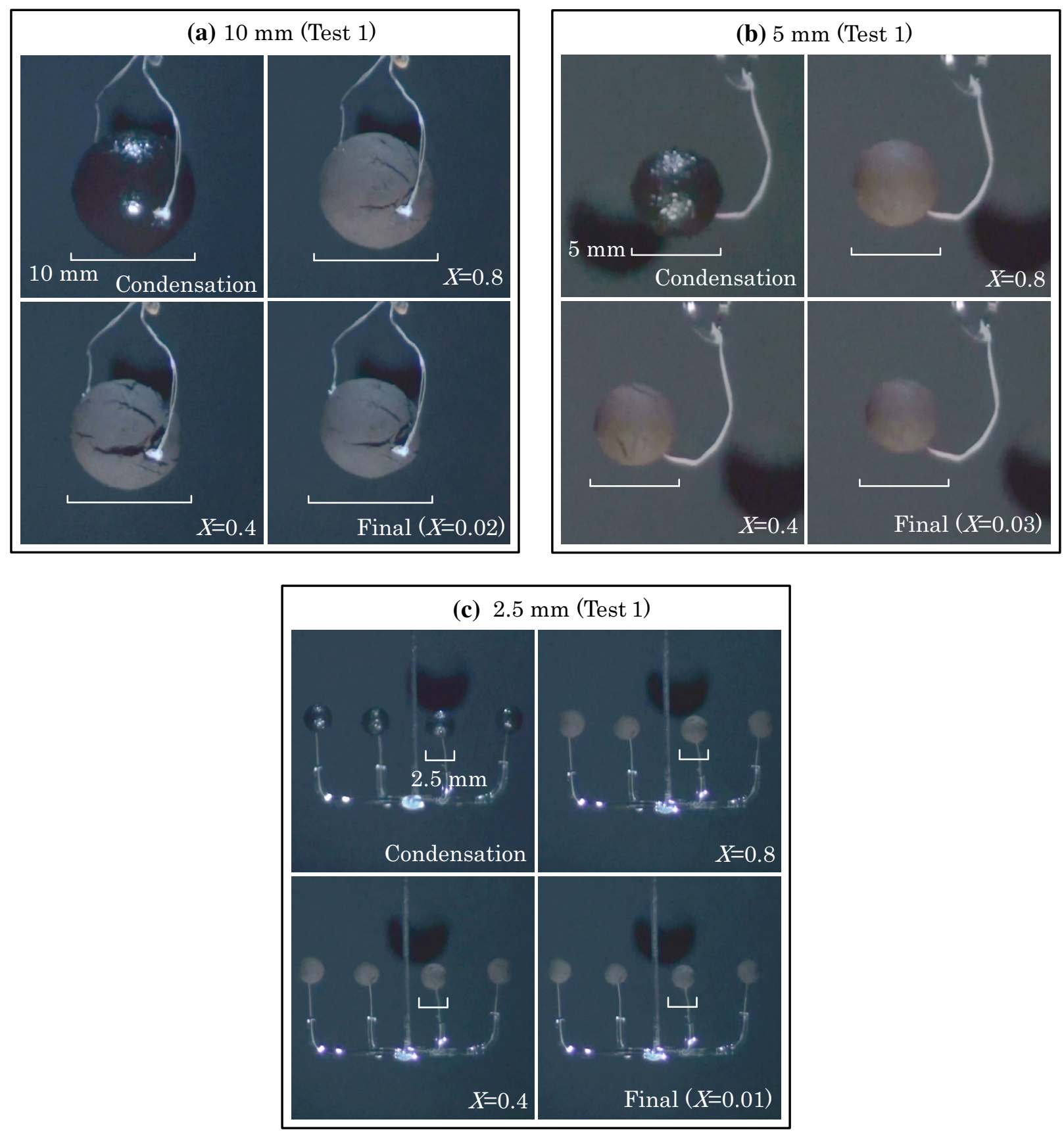

Fig. 5- Changes in appearance of the samples during drying process at $443 \mathrm{~K}\left(170{ }^{\circ} \mathrm{C}\right) .($ a $) D=10 \mathrm{~mm}(b) D=5 \mathrm{~mm}(c) D=2.5 \mathrm{~mm}$.

Figure 8 shows moisture contents, $X$, and drying rates, $-\mathrm{d} X / \mathrm{d} t$ at $T_{\mathrm{a}}=443 \mathrm{~K}\left(170{ }^{\circ} \mathrm{C}\right)$. The drying rates were smoothed by calculating the moving averages of 20 seconds. Both constant drying rate period (CDRP) and decreasing drying rate period (DDRP) were observed in all tests. The CDRP coincided with a period when the overall sample was $373 \mathrm{~K}\left(100{ }^{\circ} \mathrm{C}\right)$, suggesting that a constant heat was transferred onto the surface and consumed only by the water evaporation. It also indicated the transfer of free water from the inner part to the surface. The temperature is assumed to rise from $373 \mathrm{~K}\left(100{ }^{\circ} \mathrm{C}\right)$ when the free water is depleted there, after which the drying rate decreases until drying is apparently completed.

Similar drying characteristics were observed under other experimental conditions. In the following discussion on experimental results, CDRP is defined for simplicity as a period, where $X$ is between 1.4 and 1.0. The drying rates in CDRP were calculated from the time required to decrease $X$ from 1.4 to 1.0 and are tabulated in Table I. 


\begin{tabular}{|c|c|c|c|c|c|c|c|}
\hline \multirow{2}{*}{$\begin{array}{l}\text { Particle } \\
\text { Size, } \\
D(\mathrm{~mm})\end{array}$} & \multirow{2}{*}{$\begin{array}{c}\text { Test } \\
\text { Temperature, } \\
T_{\mathrm{a}}(\mathrm{K}) \\
\end{array}$} & \multirow{2}{*}{$\begin{array}{c}\text { Initial Moisture } \\
\text { Content, } X_{\text {ini }}\end{array}$} & \multirow{2}{*}{$\begin{array}{c}-\mathrm{d} X / \mathrm{d} t \times 10^{4}\left(\mathrm{~s}^{-1}\right) \\
(\mathrm{CDRP})\end{array}$} & \multirow{2}{*}{$\begin{array}{l}\text { Time for Complete } \\
\text { Drying, } t_{\text {comp }}(\mathrm{min})\end{array}$} & \multirow{2}{*}{$\begin{array}{c}\text { Equilibrium } \\
\text { Moisture } \\
\text { Content, } X_{\text {eq }} \\
\end{array}$} & \multicolumn{2}{|c|}{$\begin{array}{l}\text { Time Required to } \\
\text { Achieve the Target } \\
\text { Moisture Content, } \\
X=0.18, t \text { (min) }\end{array}$} \\
\hline & & & & & & Experiment & Simulation \\
\hline \multirow[t]{4}{*}{$30^{[10]}$} & 443 & 1.62 & 3.1 & 180 & 0.03 & 104 & 103 \\
\hline & 423 & 1.68 & 2.2 & 270 & 0.04 & 148 & 142 \\
\hline & 403 & 1.63 & 1.2 & 450 & 0.06 & 247 & 229 \\
\hline & 383 & 1.58 & 0.4 & 1260 & 0.12 & 765 & 689 \\
\hline \multirow[t]{4}{*}{10} & 443 & 1.75 & 12.9 & 50 & 0.02 & 26 & 27 \\
\hline & 423 & 1.74 & 8.9 & 67 & 0.04 & 38 & 38 \\
\hline & 403 & 1.66 & 4.8 & 110 & 0.06 & 67 & 63 \\
\hline & 383 & 1.68 & 1.6 & 300 & 0.13 & 210 & 172 \\
\hline \multirow[t]{4}{*}{5} & 443 & 1.61 & 31.2 & 17 & 0.03 & 10 & 10 \\
\hline & 423 & 1.66 & 22.4 & 21 & 0.04 & 14 & 14 \\
\hline & 403 & 1.63 & 13.3 & 37 & 0.04 & 23 & 23 \\
\hline & 383 & 1.61 & 4.3 & 95 & 0.14 & 79 & 71 \\
\hline \multirow[t]{4}{*}{2.5} & 443 & 1.44 & 84.6 & 5 & 0.02 & 3 & 3 \\
\hline & 423 & 1.48 & 58.5 & 7 & 0.02 & 5 & 5 \\
\hline & 403 & 1.46 & 36.1 & 11 & 0.04 & 8 & 7 \\
\hline & 383 & 1.51 & 11.7 & 35 & 0.13 & 27 & 23 \\
\hline
\end{tabular}

\section{Size Dependence of Evaporating Rates}

An evaporation rate of water from lignite, $v\left(\mathrm{~g} \mathrm{~m}^{-2} \mathrm{~s}^{-1}\right)$, is defined as the decreasing rate of $W$ divided by the apparent surface area of the sample, $\pi D^{2}$. The shrinkage of the sample was neglected in the calculation. Figure 9(a) shows the average rates during CDRP, $v_{\mathrm{CDRP}}$, calculated from $-\mathrm{d} X / \mathrm{d} t$ in Table I. The $v_{\text {CDRP }}$ shows linear relationship with $T_{\mathrm{a}}$ for each particle size; additionally, their slopes show a rough linear relationship with the reciprocal of $D$ as shown in Figure 10. $v_{\mathrm{CDRP}}$ is approximately expressed as Eq. [1]

$$
v_{\mathrm{CDRP}}=(3.56 / D+831) \cdot\left(T_{\mathrm{a}}-373\right) / 10^{5}
$$

Average evaporation rates throughout the drying process, $v_{\text {ave }}$, were calculated from time required to complete the drying and total weight of the evaporated water (Table I). As shown in Figure 9(b), $v_{\text {ave }}$ also showed linearity with $T_{\mathrm{a}}$. Assuming a linear relationship between the slopes and $D^{-1}$ shown in Figure 10, $v_{\text {ave }}$ is approximately expressed as Eq. [2]

$$
v_{\text {ave }}=(2.37 / D+358) \cdot\left(T_{\mathrm{a}}-373\right) / 10^{5}
$$

Using Eq. [2], the time to complete drying, $t_{\text {comp }}$ (seconds), can be predicted for a given particle size and temperature. The mass balance is expressed by Eq. [3]

$$
\pi D^{2} v_{\text {ave }} t_{\text {comp }}=\frac{\pi D^{3}}{6} \cdot \varphi_{\mathrm{c}, \text { ini }} \rho_{\mathrm{c}}\left(X_{\mathrm{ini}}-X_{\mathrm{eq}}\right),
$$

where $\varphi_{\text {c.ini }}$ is the initial volume fraction of dry coal in lignite, and is about 0.3 for Loy Yang lignite. $\rho_{\mathrm{c}}$ is the density of dry coal, and about $1434\left(\mathrm{~kg} \mathrm{~m}^{-3}\right) . X_{\text {ini }}$ and
$X_{\text {eq }}$ are moisture content before and after drying. Assuming $X_{\mathrm{ini}}-X_{\mathrm{eq}}$ is constant at $1.6, t_{\text {comp }}$ is expressed by Eq. [4]

$$
t_{\text {comp }}=1.15 D / v_{\text {ave }} \times 10^{5}
$$

\section{NUMERICAL MODELING}

\section{A. Physical Model}

A numerical model for drying lignite has been developed based on the physical model illustrated in Figure 11. A lignite particle was assumed to initially consist of dry coal, free water, and bound water (Figure 11(a)). "Free water" is defined as water that evaporates at $373 \mathrm{~K}\left(100{ }^{\circ} \mathrm{C}\right)$ under atmospheric pressure, and accounts for moisture content from the initial value (about 1.6 ) to $0.56 .^{[13,14]}$ The remainder is defined as "bound water" that evaporates above $373 \mathrm{~K}$ $\left(100{ }^{\circ} \mathrm{C}\right)$. Volume fractions of coal, water, and steam $\left(\varphi_{\mathrm{c}}, \varphi_{\mathrm{w}}, \varphi_{\mathrm{s}}\right)$ are $0.3,0.7$, and 0 , respectively, in the initial state. When free water evaporates during the drying process, its space becomes occupied by steam as shown in Figure 11(b): meanwhile, free water is supplied from the inside to the surface, resulting in CDRP. After free water on the surface has evaporated completely, the temperature rises from $373 \mathrm{~K}\left(100{ }^{\circ} \mathrm{C}\right)$, and DDRP begins with the evaporation of bound water (Figure 11(c)).

Figure 12 shows a simulation model. If a lignite particle is assumed to be isotropic, a one-dimensional model can be used. A particle is divided into 51 concentric spherical shells with an initial thickness of 


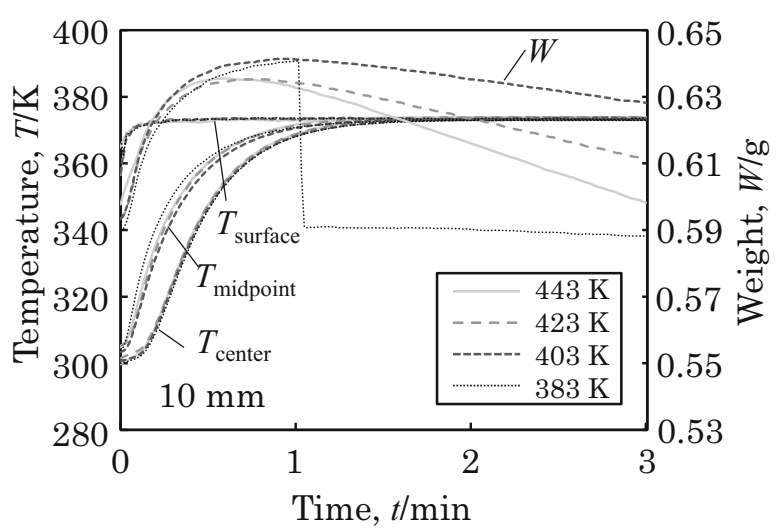

(a)

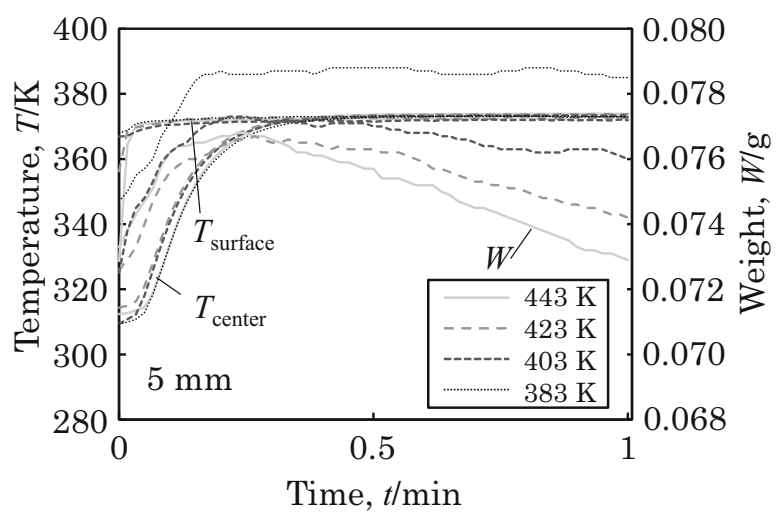

(b)

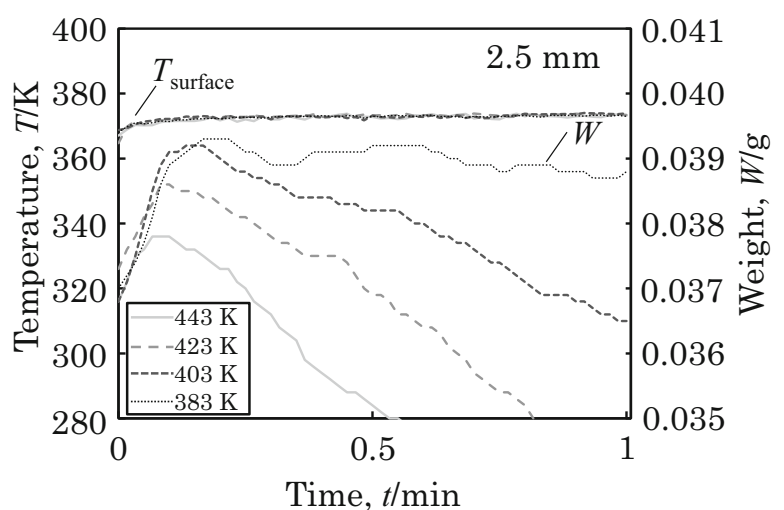

(c)

Fig. 6-Temperatures and weights of the samples $(a) 10 \mathrm{~mm},(b)$ $5 \mathrm{~mm}$, and $(c) 2.5 \mathrm{~mm}$ in diameter during the initial period.

the initial radius $\left(R_{\mathrm{ini}}=D / 2=5,2.5\right.$ and $\left.1.25 \mathrm{~mm}\right)$ divided by 50 , except for surface and center layers, which have the initial thickness of $R_{\text {ini }}$ divided by 100 . The 51 layers are numbered from surface (1st) to center (51st), and outer radius of the $n$-th layer is represented by $r_{n}$.

Weight and temperature in each layer are assumed to be homogeneous, and the temperature of $n$-th layer, $T_{n}$, is represented by the midpoint in the radial direction for $2 \leq n \leq 50$. For the 1 st and 51st layers, temperatures are

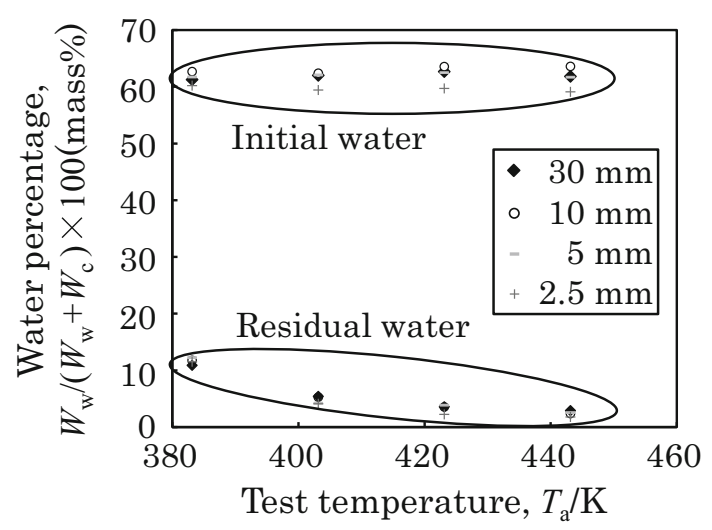

Fig. 7-Initial and residual water percentages.

represented by the surface and center of the particle, respectively. Distance from the representative point of $n$-th layer to the next layer is defined as $d_{n}$.

Parameters used in this simulation are listed in Table II. Transfer and consumption of heat, evaporation and transfer of water, shrinkage of lignite, and behavior of water condensed on the surface are considered as explained in the following sections. The model developed in a previous study ${ }^{[10]}$ was modified in some respects, and drying of lignite $30 \mathrm{~mm}$ in diameter was then recalculated using the new model and compared with the previous simulation.

\section{B. Heat Transfer to the Surface}

Initial temperatures of lignite are determined to be $303 \mathrm{~K}$ and $318 \mathrm{~K}\left(30{ }^{\circ} \mathrm{C}\right.$ and $\left.45^{\circ} \mathrm{C}\right)$ for the particle sizes of 10 and $5 \mathrm{~mm}$, respectively, from Figure 6 . Initial temperature of lignite particles $2.5 \mathrm{~mm}$, which is believed to be higher than that of the samples $5 \mathrm{~mm}$, is assumed to be $333 \mathrm{~K}\left(60{ }^{\circ} \mathrm{C}\right)$. When the temperature of the 1st layer, $T_{1}$, is below $373 \mathrm{~K}\left(100{ }^{\circ} \mathrm{C}\right)$, heat flux to the surface, $\Delta Q_{1}$, is believed to be accomplished mainly by the condensation of steam. Assuming the condensed water on the surface is $373 \mathrm{~K}\left(100{ }^{\circ} \mathrm{C}\right)$, the heat flux is expressed by Eq. [5]

$$
\Delta Q_{1}=h_{\text {cond }} \cdot 4 \pi r_{1}^{2}\left(373-T_{1}\right) \cdot \Delta t, \text { for } T_{1}<373,
$$

where $h_{\text {cond }}$ is the condensing heat transfer coefficient and $r_{1}$ equals the radius of the particle, $R_{\text {ini }}$. $h_{\text {cond }}$ was assumed from experimental results to be $5000 \mathrm{~W} \mathrm{~m}^{-2} \mathrm{~K}^{-1}$. Time step, $\Delta t$, is 0.001 second in this calculation.

After $T_{1}$ reaches $373 \mathrm{~K}\left(100{ }^{\circ} \mathrm{C}\right)$, the temperature is maintained until the water on the surface dries up. Therefore, $\Delta Q_{1}$ equals heat flux to the inner layer, $\Delta Q_{2}$, which is defined in Section IV-C.

$$
\Delta Q_{1}=\Delta Q_{2}, \text { for } T_{1}=373 \text { and } M_{\text {surf }}>0,
$$

where $M_{\text {surf }}$ is the weight of water on the surface introduced in Section IV-E. 


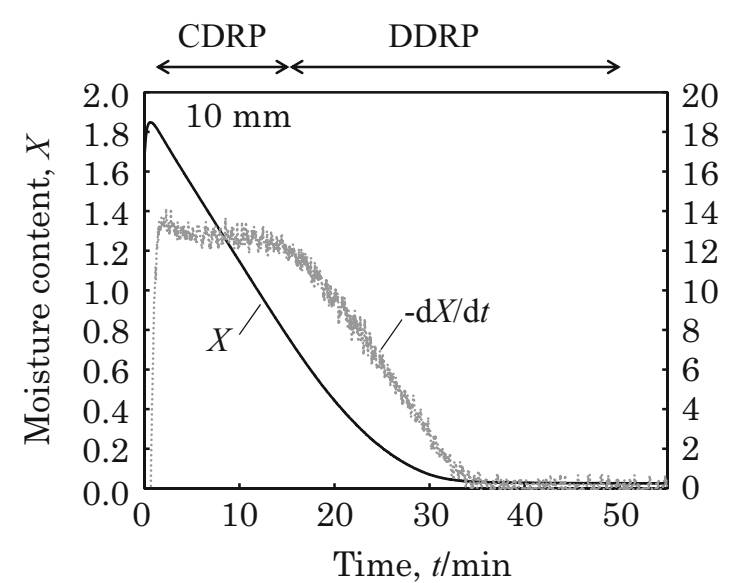

(a)

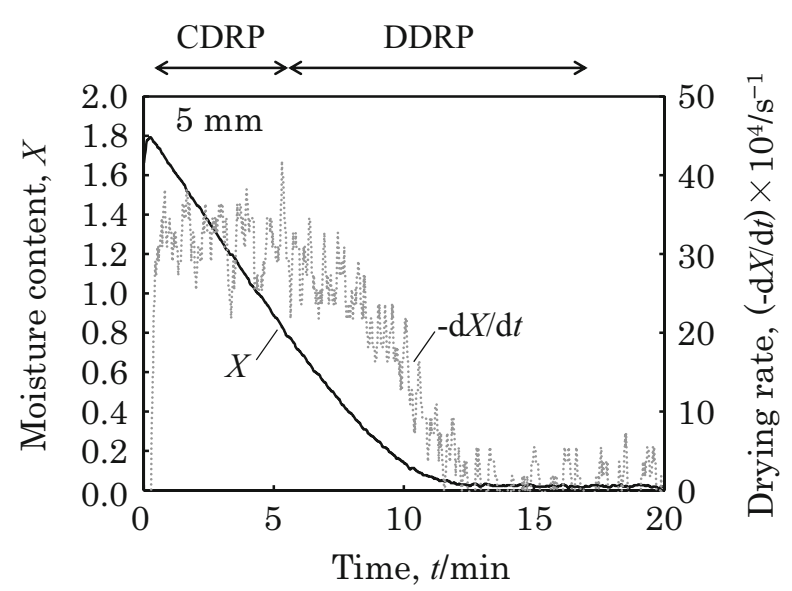

(b)

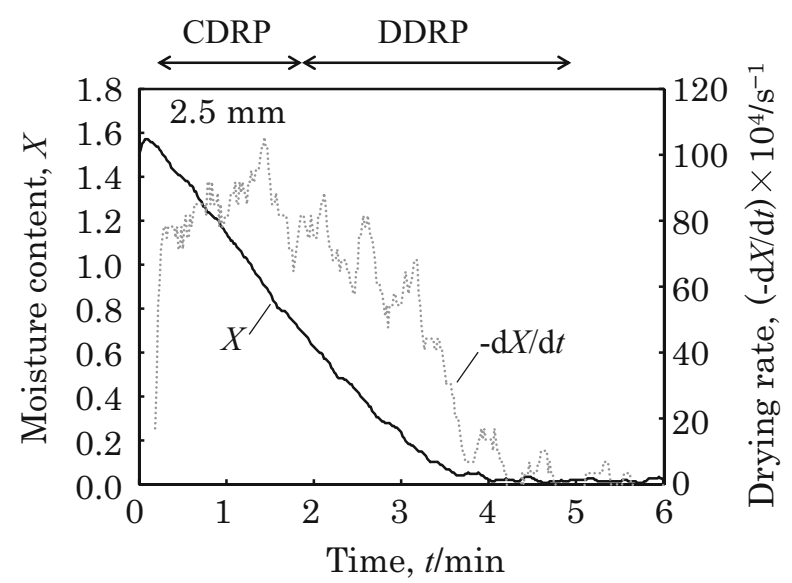

(c)

Fig. 8-Moisture contents and drying rates of the samples (a) $10 \mathrm{~mm},(b) 5 \mathrm{~mm}$, and (c) $2.5 \mathrm{~mm}$ in diameter at $443 \mathrm{~K}\left(170^{\circ} \mathrm{C}\right)$.

After water on the surface evaporates, $\Delta Q_{1}$ is assumed to be accomplished by convection and radiation. Although the previous calculation used general formulas for heat transfer by natural convection, ${ }^{[10]}$ this study
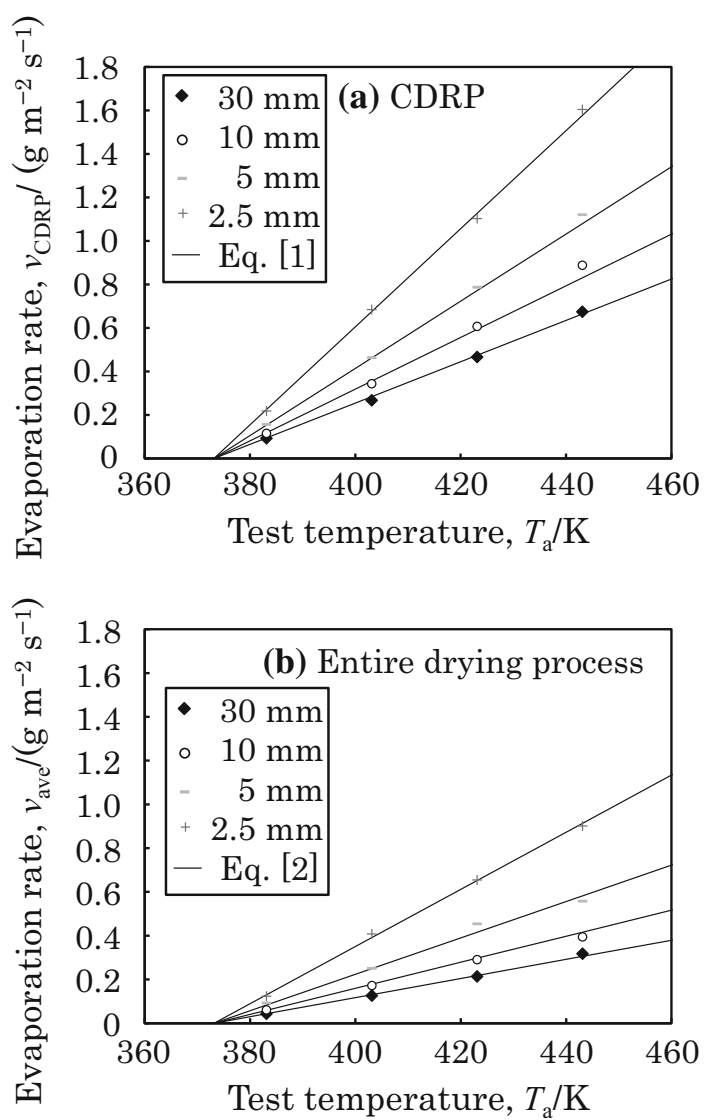

Fig. 9-Evaporation rates during (a) the constant drying rate period and $(b)$ entire drying process.

uses the heat transfer coefficient, $h_{\mathrm{a}}$, derived from experimental results. Because $\Delta Q_{1}$ is believed to be used only for evaporation of water during CDRP, the linear relationships in Figure 9(a) are regarded as an indication of a proportional relationship between $\Delta Q_{1}$ and $T_{\mathrm{a}}-T_{1}$. Equation [7] was derived from Eq. [1] and used in this model.

$$
h_{\mathrm{a}}=v_{\mathrm{CDRP}} L /\left(T_{\mathrm{a}}-373\right)=0.0401 / r_{1}+18.7,
$$

where $L$ is the latent heat of free water at $373 \mathrm{~K}$ $\left(100{ }^{\circ} \mathrm{C}\right) . \Delta Q_{1}$ is expressed by Eq. [8]

$\Delta Q_{1}=h_{\mathrm{a}} \cdot 4 \pi r_{1}^{2}\left(T_{\mathrm{a}}-T_{1}\right) \cdot \Delta t, \quad$ for $T_{1} \geq 373$ and $M_{\text {surf }}=0$

\section{Heat Transfer Inside the Lignite Particle}

Heat input to the $n$-th layer from the outer layer by conduction, $\Delta Q_{n}$, is expressed by Eq. [9]

$$
\begin{aligned}
& \Delta Q_{n}=k_{n-1, n} /\left(d_{n-1}+d_{n}\right) \cdot 4 \pi r_{n}^{2}\left(T_{n-1}-T_{n}\right) \cdot \Delta t, \\
& \quad \text { for } 2 \leq n \leq 51,
\end{aligned}
$$

where $k_{n-1, n}$ is thermal conductivity between adjacent layers. $k_{n-1, n}$ is expressed by Eq. [10] 


$$
k_{n-1, n}=\left(d_{n-1}+d_{n}\right) /\left(\frac{d_{n-1}}{k_{n-1}}+\frac{d_{n}}{k_{n}}\right), \quad \text { for } 2 \leq n \leq 51
$$

$$
\begin{gathered}
k_{n}=\varphi_{\mathrm{w}} k_{\mathrm{w}}+\varphi_{\mathrm{c}} k_{\mathrm{c}}+\varphi_{\mathrm{s}} k_{\mathrm{s}} \\
\varphi_{\mathrm{w}}+\varphi_{\mathrm{c}}+\varphi_{\mathrm{s}}=1,
\end{gathered}
$$

where $k_{n}$ is thermal conductivity of the layer calculated using Eq. [11] from thermal conductivity and volume

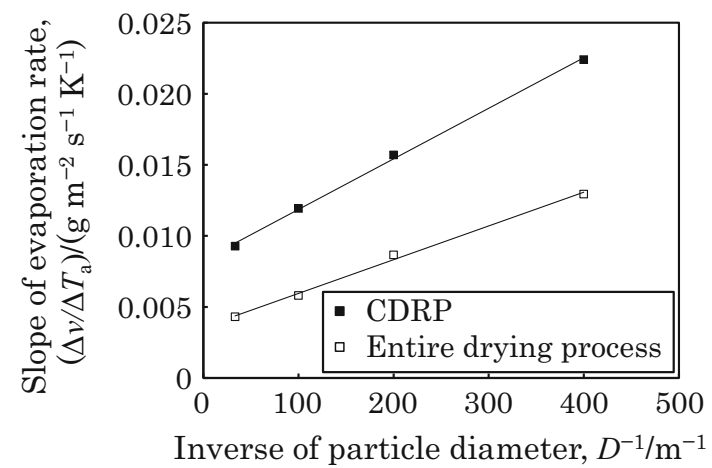

Fig. 10-Relationship between slope of evaporation rate in Fig. 9 and inverse of particle diameter. fraction of water, coal, and steam (Table II). There is no heat transfer from the center layer $(n=51)$.

\section{Heat Consumption}

Difference between heat input and output of the $n$-th layer, $\Delta Q_{n}-\Delta Q_{n+1}$, is consumed by rising temperature or evaporation of water depending on conditions. The heat consumption is expressed by Eq. [13]

$$
\begin{aligned}
\Delta Q_{n}-\Delta Q_{n+1}= & \left(C_{\mathrm{c}} M_{\mathrm{c}, n}+C_{\mathrm{w}}\left(M_{\mathrm{w}, n}-\Delta M_{\mathrm{evap}, n}\right)\right) \Delta T_{n} \\
& +\Delta M_{\mathrm{evap}, n} \Delta H_{\text {evap }}
\end{aligned}
$$

where $C_{\mathrm{c}}$ and $C_{\mathrm{w}}$ are the specific heat of coal and water, $M_{\mathrm{c}, n}$ and $M_{\mathrm{w}, n}$ are the weight of coal and water in the layer, $\Delta T_{n}$ is the temperature increase, $\Delta M_{\mathrm{evap}, n}$ is the weight of water evaporated from the layer, and $\Delta H_{\text {evap }}$ is the enthalpy change of the water evaporation. Thermal capacity of steam is neglected.

When $T_{n}$ is below $373 \mathrm{~K}\left(100{ }^{\circ} \mathrm{C}\right)$, the heat is consumed only to increase the temperature, and Eq. [13] is substituted by Eq. [14]

$$
\Delta Q_{n}-\Delta Q_{n+1}=\left(C_{\mathrm{c}} M_{\mathrm{c}, n}+C_{\mathrm{w}} M_{\mathrm{w}, n}\right) \Delta T_{n}
$$

After $T_{n}$ reaches $373 \mathrm{~K}\left(100{ }^{\circ} \mathrm{C}\right)$, the heat is used only for evaporating free water. Because $\Delta T_{n}$ is zero during

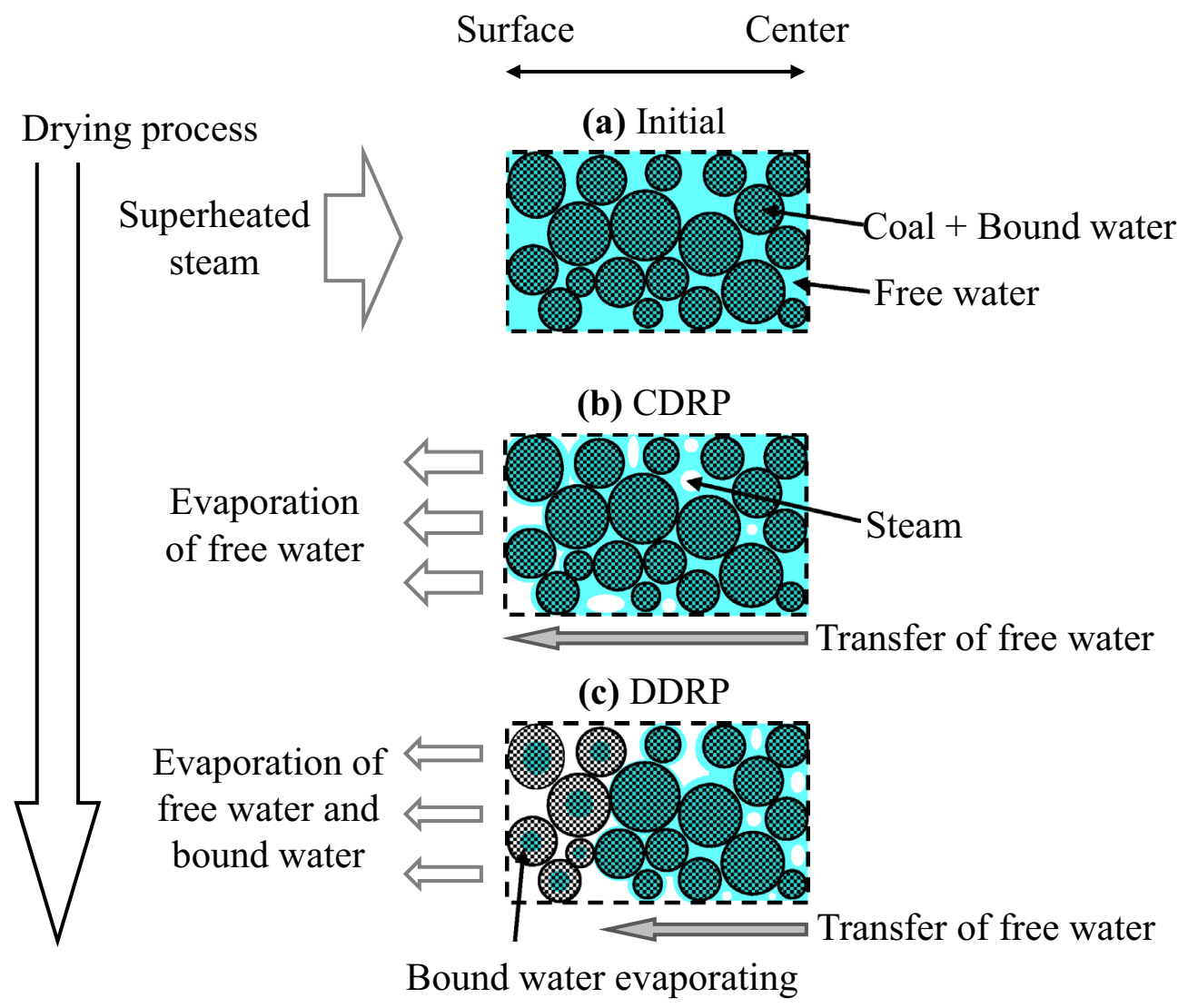

Fig. 11-Schematic illustration of drying process. (a) Initial state, $(b)$ constant drying rate period, and $(c)$ Decreasing drying rate period. 


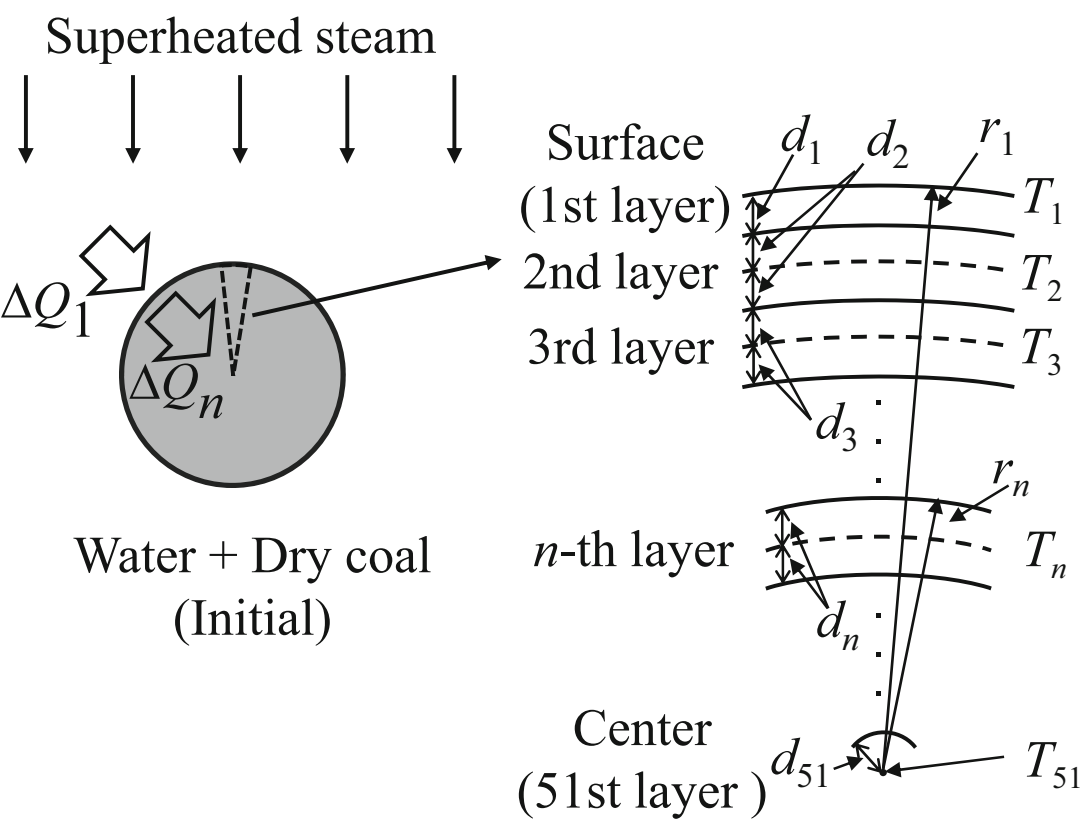

Fig. 12-Simulation model.

this period, Eq. [13] is substituted by Eq. [15], where $L$ is the latent heat of free water at $373 \mathrm{~K}\left(100{ }^{\circ} \mathrm{C}\right)$.

$$
\Delta Q_{n}-\Delta Q_{n+1}=\Delta M_{\mathrm{evap}, n} L
$$

When the moisture content in the layer, $X_{n}$, becomes 0.56 , free water is regarded as having evaporated completely. ${ }^{[10,13,14]}$ Thereafter, the heat is used for both evaporating bound water and increasing temperature. The Newton method is used to simulate drying during this period, assuming the relationship between $T$ and $X$ follows the equilibrium moisture content curve in Figure 13, which was assumed in the previous study ${ }^{[10]}$

When bound water evaporates above $373 \mathrm{~K}\left(100{ }^{\circ} \mathrm{C}\right)$, $\Delta H_{\text {evap }}$ is assumed to be larger than that for free water. In the previous study, ${ }^{[10]} \Delta H_{\text {evap }}$ was expressed as a function of the evaporating temperature based on thermodynamic information on bound water in lignite. ${ }^{[15]}$ This study used the same equation shown by Eq. [16]

$\Delta H_{\text {evap }}=2.932 \times 10^{6}-6.76 \times 10^{5} \times \exp (-0.077(T-373))$ $X$.

Figure 14 shows the relationship between $\Delta H_{\text {evap }}$ and

\section{E. Condensation, Exudation, and Water Droplets Falling on the Surface}

In the same manner as the previous study, ${ }^{[10]}$ the temperature dependence of water density was considered because expansion of water in the lignite was significant during the condensation period (Table II). The expanded water was assumed to exude on the surface and to form droplets with condensed steam.
Therefore, the weight of the water on the surface, $M_{\text {surf }}$, is defined as Eq. [17]

$$
\begin{aligned}
& \Delta M_{\text {surf }}=\left(\Delta Q_{1}-h_{\mathrm{a}} \cdot 4 \pi r_{1}^{2}\left(T_{\mathrm{a}}-373\right) \cdot \Delta t\right) / L+\Delta M_{\mathrm{ex}}, \\
& \quad \text { for } T_{1} \leq 373
\end{aligned}
$$

where $\Delta M_{\text {ex }}$ is the weight of the exuded water. $M_{\text {surf }}$ is 0 in the initial state.

Sizes of the falling droplets and their frequency depended on $R_{\text {ini }}$ in experiments. For convenience, this study used the model shown in Figure 14 to formulate the relationship between the size of a droplet and $R_{\text {ini }}$. Water was assumed to form a thin layer on the surface of lignite and to have a hemispheric droplet hanging from its bottom. Angle $\theta$ in Figure 14 gives the relation of $\sin \theta=r_{\mathrm{wd}} / R_{\text {ini }}$, where $r_{\mathrm{wd}}$ is the radius of the droplet. The droplet was assumed to be bound under the lignite by surface tension, of which the vertical component is approximately expressed by $2 \pi r_{\mathrm{wd}} \gamma \times \cos \theta$. If the gravitational force acting on the droplet is expressed as $4 \pi r_{\mathrm{wd}}^{3} / 3 \times \mathrm{g} \times \mathrm{A}$, the bonding force between lignite and water droplet equals the gravitational force when

$$
\frac{r_{\mathrm{wd}}^{2}}{\cos \theta}=\frac{3 \gamma}{2 \mathrm{gA}}
$$

The relation of $\cos \theta=\sqrt{1-\left(r_{\mathrm{wd}} / R_{\text {ini }}\right)^{2}}$ gives Eq. [19]

$$
r_{\mathrm{wd}}=\left(\frac{\sqrt{\left(E / R_{\mathrm{ini}}\right)^{4}+4 E^{2}}-\left(E / R_{\mathrm{ini}}\right)^{2}}{2}\right)^{1 / 2}
$$

where $E=3 \gamma / 2 \mathrm{gA}$.

In measurements of the samples with $D=10 \mathrm{~mm}$, the weight of a falling droplet observed at $383 \mathrm{~K}$ 


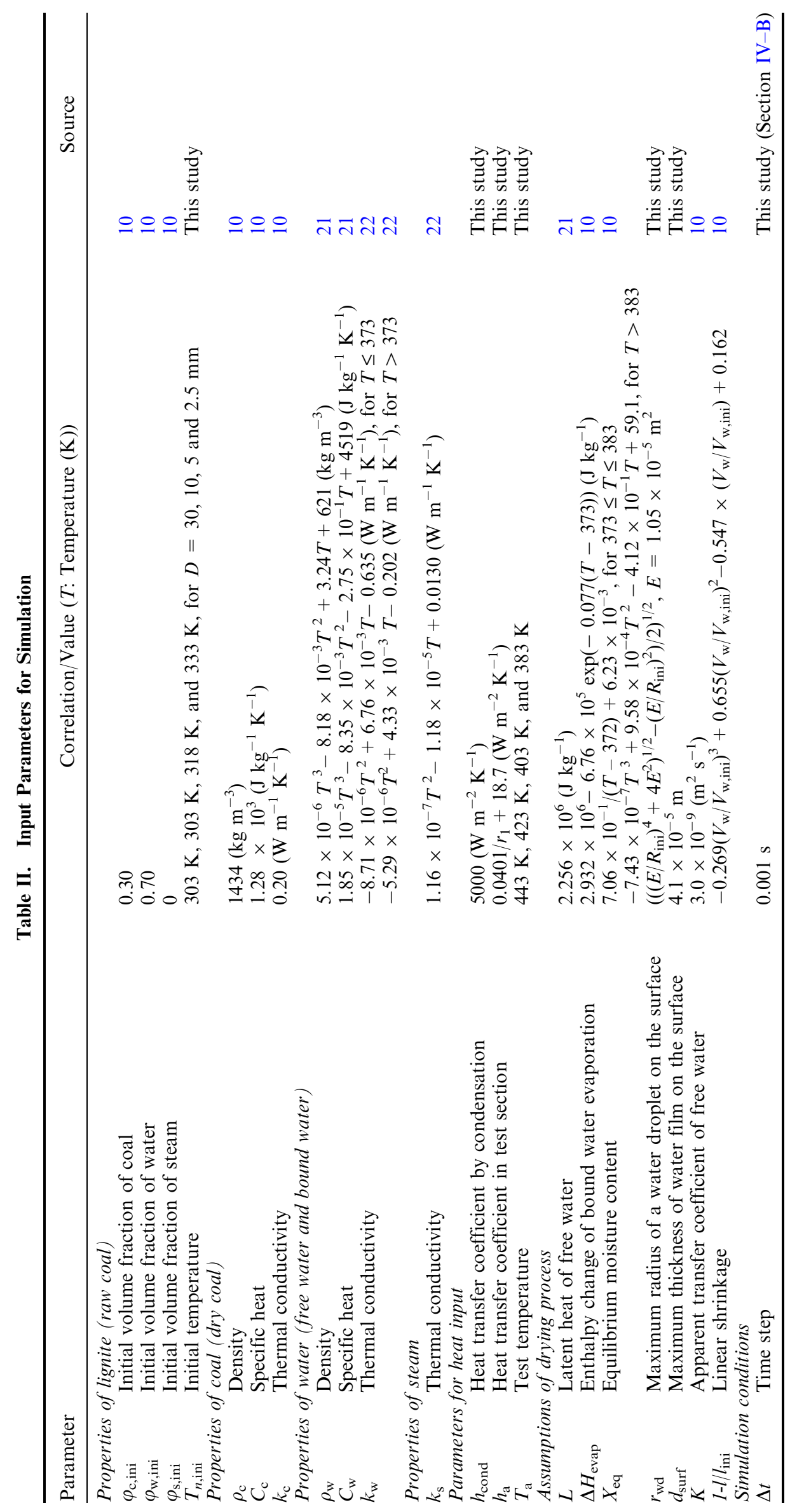


$\left(110^{\circ} \mathrm{C}\right.$ ) was $0.05 \mathrm{~g}$ (Figure 6). On the assumption that the droplet is hemispheric, $r_{\mathrm{wd}}$ is calculated to be $2.9 \times 10^{-3} \mathrm{~m}$, and thus $E$ in Eq. [19] is $1.05 \times$ $10^{-5} \mathrm{~m}^{2}$. Using this value, $r_{\mathrm{wd}}$ for $D=30 \mathrm{~mm}$ is calculated to be $3.2 \times 10^{-3} \mathrm{~m}$ by Eq. [19]. Weight of the hemispheric droplet with this radius is $0.07 \mathrm{~g}$, which gives an acceptable fit with the weight of droplet observed in the previous study ${ }^{[10]}$ Consequently, Eq. [19] with $E=1.05 \times 10^{-5} \mathrm{~m}^{2}$ was adopted in simulation, and the relationship between $R_{\text {ini }}$ and $r_{\text {wd }}$ is shown in Figure 14. On the other hand, the thickness of water film formed on the surface was estimated from simulation results in the previous study, ${ }^{[10]}$ where a water droplet of $0.08 \mathrm{~g}$ fell from a $30 \mathrm{~mm}$ particle when the weight of surface water became $0.19 \mathrm{~g}$. Assuming the remaining $0.11 \mathrm{~g}$ of water was forming a layer, its thickness, $d_{\text {surf }}$, was $4.1 \times 10^{-5} \mathrm{~m}$. A falling droplet is assumed to occur if the weight of surface water, $M_{\text {surf }}$, exceeds the sum of a hemispheric water droplet with

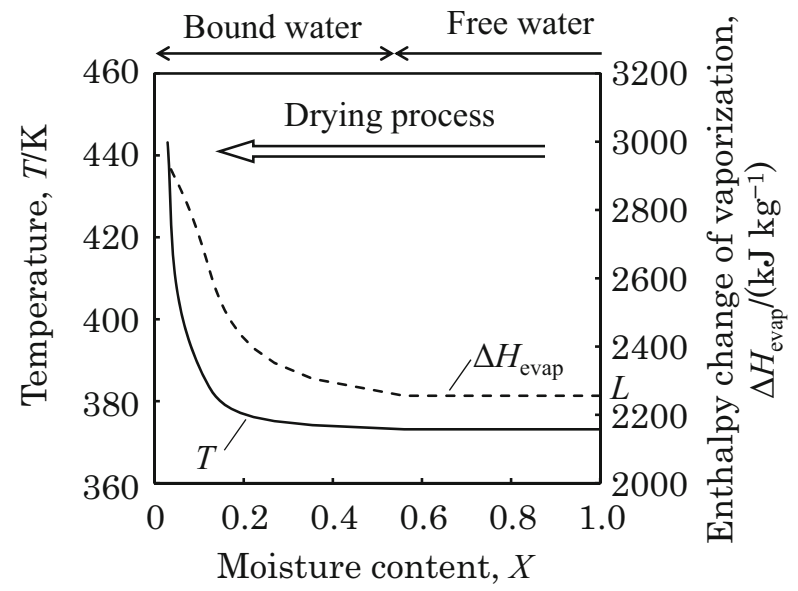

Fig. 13-Relationships between moisture content, enthalpy change of water vaporization and evaporating temperature under atmospheric pressure. radius of $r_{\mathrm{wd}}$ and water film with a thickness of $4.1 \times 10^{-5} \mathrm{~m}$.

\section{F. Transfer of Free Water}

Free water in lignite is thought to be transferred by capillary pressure gradient, diffusion, or vapor pressure gradient. ${ }^{[16,17]}$ Because of the difficulty in formulating these factors, previous study ${ }^{[10]}$ assumed that the transfer can be approximately expressed by the moisture content as in Eq. [20]

$$
\begin{aligned}
& \Delta M_{\text {trans }, n}=-K \rho_{\mathrm{c}} \cdot \frac{4 \pi r_{n+1}^{2}}{d_{n}+d_{n+1}}\left(X_{n}-X_{n+1}\right) \cdot \Delta t, \\
& \quad \text { for } n \leq 50 \text { and } X_{n+1}>0.56,
\end{aligned}
$$

where $\Delta M_{\text {trans }, n}$ is water transfer from $(n+1)$ th layer to $n$-th layer, and $K$ is the apparent transfer coefficient, and

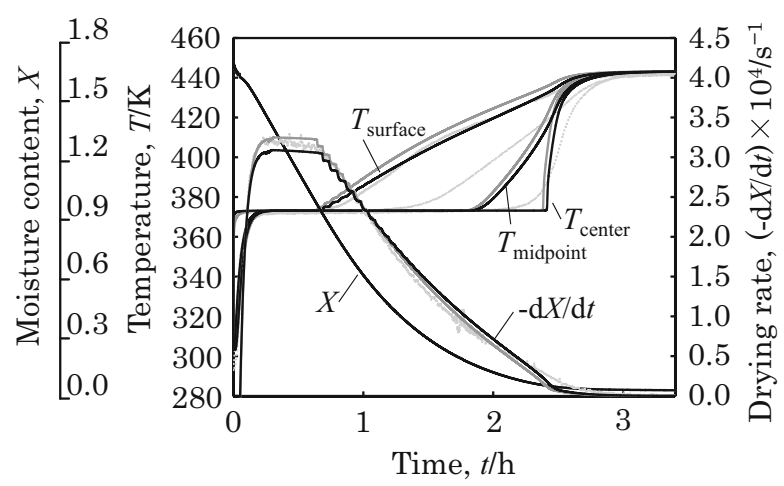

Fig. 15-Simulated moisture content, drying rate, and temperatures of the samples $30 \mathrm{~mm}$ in diameter at a test temperature of $443 \mathrm{~K}$ $\left(170{ }^{\circ} \mathrm{C}\right)$ compared to those in a previous study. ${ }^{[10]}$ Black solid lines represent simulation results in this study. Gray solid lines and dashed lines represent simulation and experimental results, respectively, in a previous study.
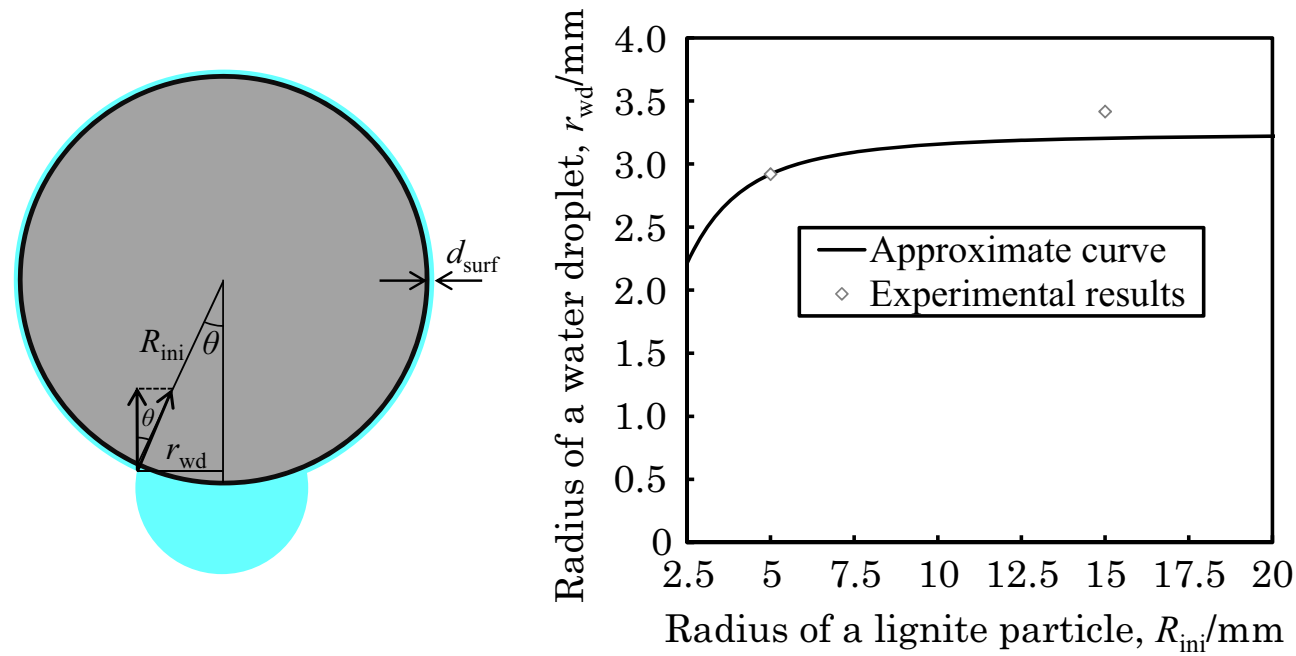

Fig. 14 - Simple model for a water droplet and film attached to the surface of a lignite particle and relationship between the radius of a lignite particle and that of a water droplet. 


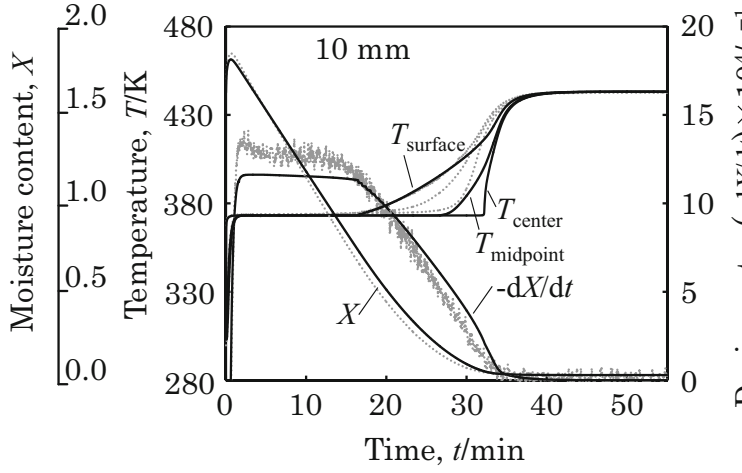

(a)

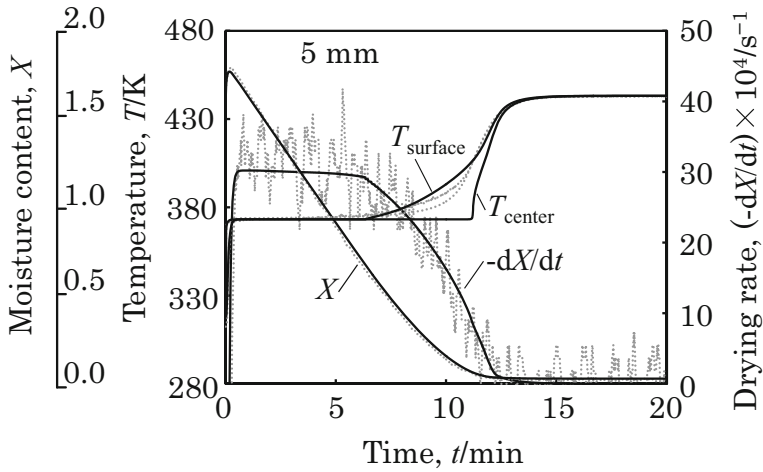

(b)

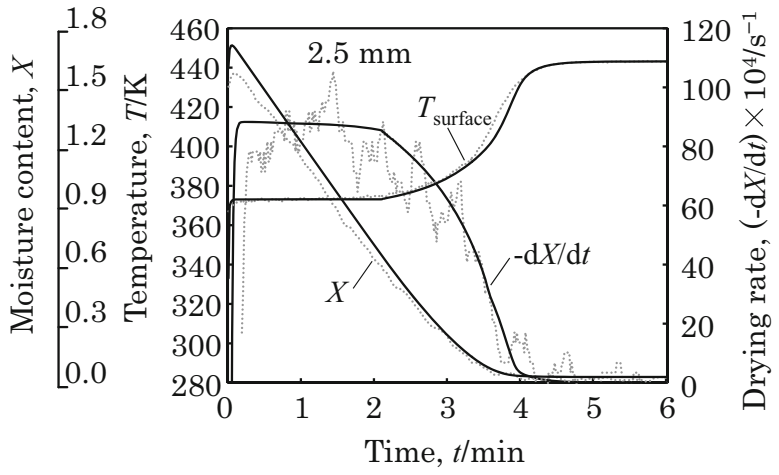

(c)

Fig. 16- Simulated moisture contents, drying rates, and temperatures of the samples (a) $10 \mathrm{~mm}$, (b) $5 \mathrm{~mm}$, and (c) $2.5 \mathrm{~mm}$ in diameter at a test temperature of $443 \mathrm{~K}\left(170^{\circ} \mathrm{C}\right)$. Black solid lines and gray dashed lines represent results of simulation and experiments, respectively.

was assumed to be $3 \times 10^{-9}\left(\mathrm{~m}^{2} \mathrm{~s}^{-1}\right)$ which fitted experimental results in the previous study. ${ }^{[10]}$ This study adopts Eq. [20] and the same value for $K$ in modeling.

\section{G. Shrinkage}

When water in lignite evaporates, its space is then occupied by steam (Section IV-A) in this model. To simulate the volume change of lignite during the drying, the volume of steam is assumed to decrease. Linear shrinkage of lignite, $1-l / l_{\text {ini }}$, caused by drying has been

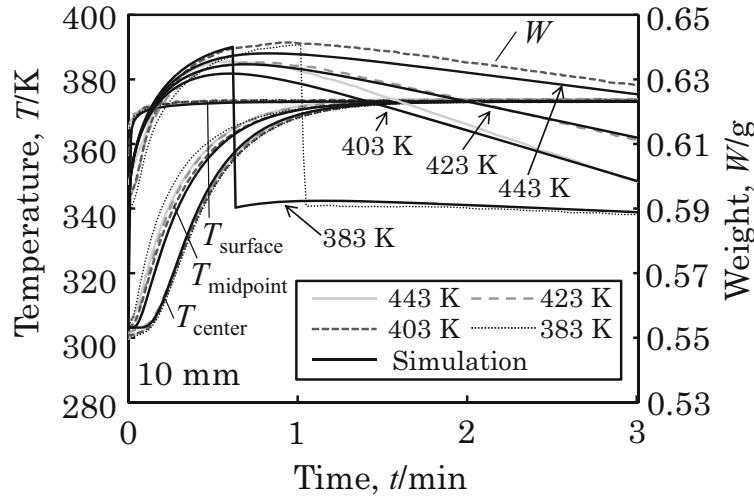

(a)

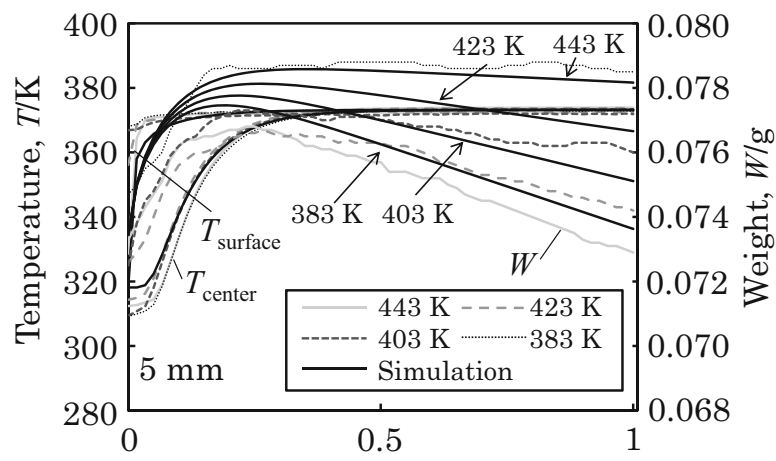

Time, $t / \mathrm{min}$

(b)

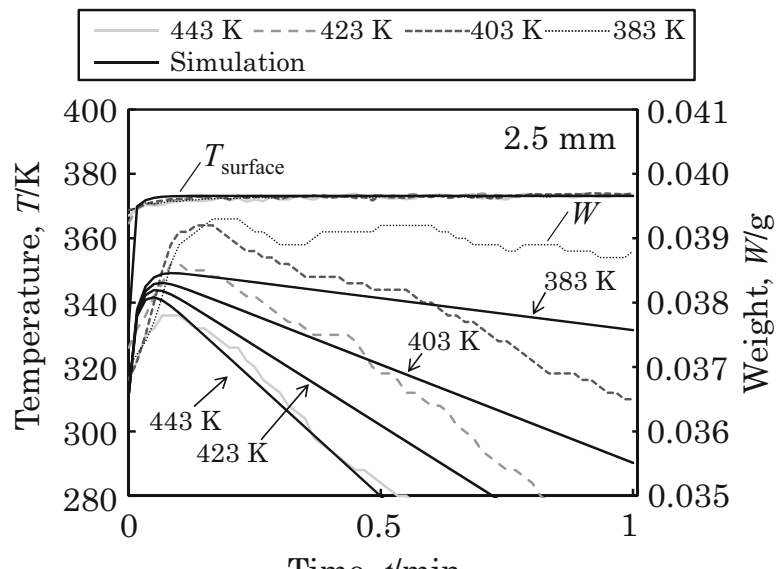

Time, $t / \mathrm{min}$

(c)

Fig. 17-Simulated temperatures and weights compared to experimental results during the initial period. (a) $10 \mathrm{~mm}$, (b) $5 \mathrm{~mm}$, and (c) $2.5 \mathrm{~mm}$.

examined in previous study, and expressed as a function of water volume fraction ${ }^{[10]}$

$$
\begin{aligned}
1-l / l_{\text {ini }}= & -0.269 \times\left(\frac{V_{\mathrm{w}}}{V_{\mathrm{w}, \text { ini }}}\right)^{3}+0.655 \times\left(\frac{V_{\mathrm{w}}}{V_{\mathrm{w}, \text { ini }}}\right)^{2} \\
& -0.547 \times\left(\frac{V_{\mathrm{w}}}{V_{\mathrm{w}, \text { ini }}}\right)+0.162 .
\end{aligned}
$$




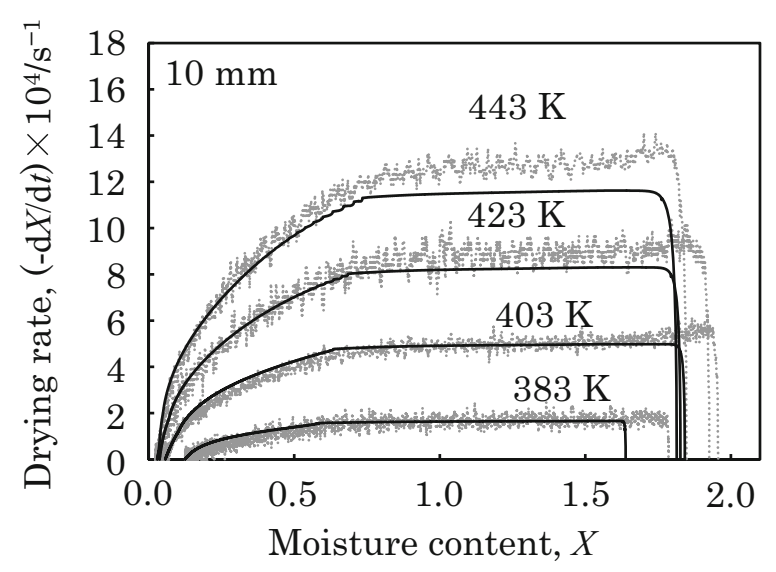

(a)

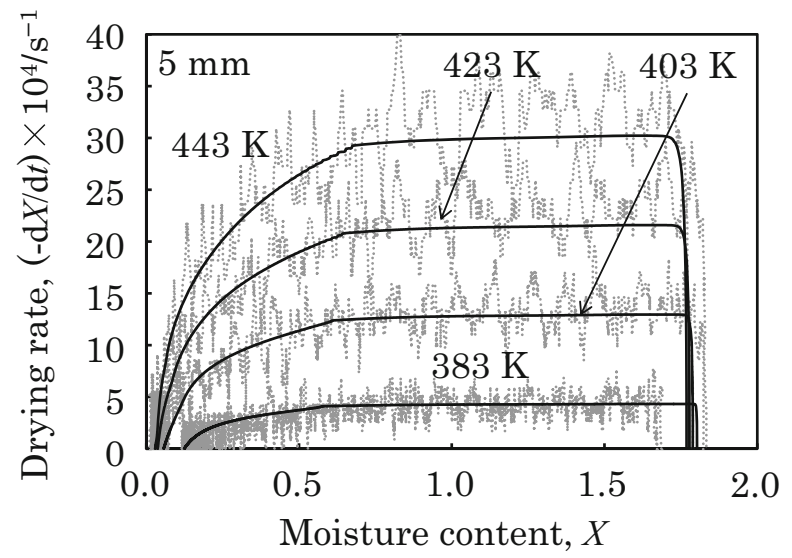

(b)

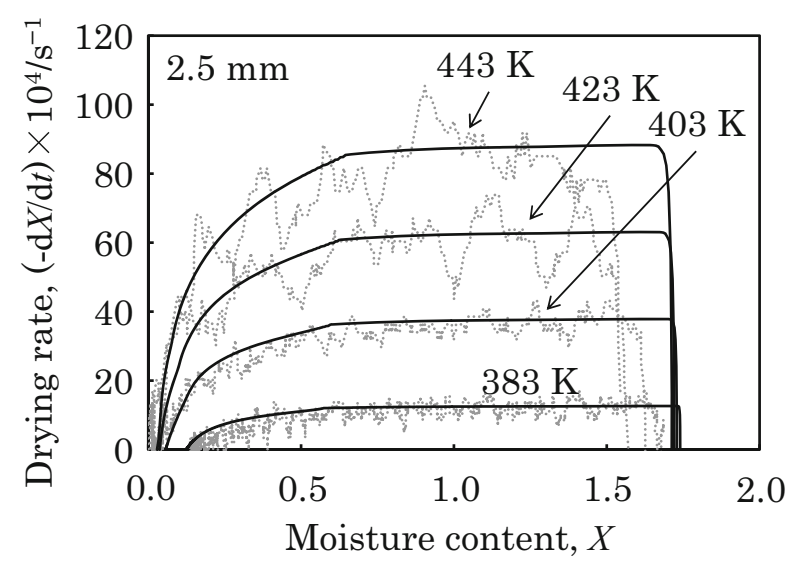

(c)

Fig. 18-Drying characteristic curves of samples (a) mm 10, (b) $5 \mathrm{~mm}$, and $(c) 2.5 \mathrm{~mm}$ in diameter (experimental and simulation results). Black solid lines and gray dashed lines represent results of simulation and experiments, respectively.

In the simulation of drying behaviors, thickness of each layer was defined as the product of initial thickness and the linear shrinkage, from which $d_{n}$ and $r_{n}$ were also derived in every time step. Volume loss is counted as the change in the volume of steam at each layer.

\section{SIMULATION RESULTS AND DISCUSSION}

In Figure 15, simulation results for a lignite particle with $D=30 \mathrm{~mm}$ dried at $443 \mathrm{~K}\left(170{ }^{\circ} \mathrm{C}\right)$ are compared with the previous model. ${ }^{[10]}$ Although the modification of heat input (Section IV-B) caused minor deviations of the simulated drying rates and temperatures, the moisture contents coincided well, suggesting a practical applicability of a new model to coarse lignite particles.

Figure 16 shows simulation results compared to experimental results at $443 \mathrm{~K}\left(170{ }^{\circ} \mathrm{C}\right)$ for the samples with $D=10,5$, and $2.5 \mathrm{~mm}$, respectively. The experimental drying rates were smoothed by calculating their moving averages of 20 seconds. Simulated moisture contents, drying rates, and $T_{\text {surface }}$ agree well with the experimental results. Temperatures of inner parts ( $T_{\text {midpoint }}$ and $T_{\text {center }}$ ), however, started rising from $373 \mathrm{~K}\left(100^{\circ} \mathrm{C}\right)$ earlier in the experiments than in the simulated results. One possible reason for these deviations is measurement errors caused by conductive heat transfer along thermocouples from outside a sample, as reported in other studies. ${ }^{[8,18]}$ Another reason is thought to be the diffusion of bound water in lignite, which is not considered in this model.

Figure 17 shows temperatures and weights of lignite during the initial period of drying. A falling droplet was observed in the simulation for a sample $10 \mathrm{~mm}$ in diameter at $383 \mathrm{~K}\left(110^{\circ} \mathrm{C}\right)$, similar to the experiment. Figure 18 shows the drying characteristic curves from experimental and simulation results to be in good agreement.

For confirmation of the availability of the simulation model, time required to achieve the target moisture content was calculated. This target value is set at 15 mass pct, ${ }^{[19,20]}$ which corresponds to $X=0.18$. As shown in Table I, differences between the calculation and experiments are larger at lower drying temperature. This is because the evaporation of water becomes slight toward the end of drying especially at low temperatures, and the results seem acceptable.

\section{CONCLUSIONS}

The drying of 10, 5, and 2.5-mm-diameter lignite particles was observed in superheated steam at temperatures ranging from $383 \mathrm{~K}$ to $443 \mathrm{~K}\left(110^{\circ} \mathrm{C}\right.$ to $\left.170{ }^{\circ} \mathrm{C}\right)$ under atmospheric pressure. Weights and temperatures of the samples were measured during the drying, and the results showed typical drying characteristics including CDRP and DDRP. Dependence of the drying rate on particle size was determined, and the heat transfer from superheated steam to lignite surface was evaluated as a function of this size. Generation of cracks during drying also depended on the temperature and particle size. 
A numerical model previously developed for the drying of a coarse lignite particle has been modified making it applicable to smaller particles based on the presented results. The model can predict the behavior of lignite particles ranging from a few millimeters to several centimeters in size and dried at temperatures from $383 \mathrm{~K}$ to $443 \mathrm{~K}\left(110{ }^{\circ} \mathrm{C}\right.$ to $\left.170{ }^{\circ} \mathrm{C}\right)$, making it applicable for simulations of drying behaviors of lignite of a variety size distribution in various dryers when an appropriate heat transfer coefficient is given.

\section{ACKNOWLEDGMENTS}

The authors acknowledge financial support from the Japan Coal Energy Center. Lignite for samples was supplied by Mitsubishi Heavy Industries, LTD.

\section{LIST OF SYMBOLS}

C Specific heat at constant pressure, $\mathrm{J} \mathrm{kg}^{-1} \mathrm{~K}^{-1}$

$D \quad$ Initial diameter of the sample, $\mathrm{m}$

$d$ Distance from the representative point of the layer to the next layer, $\mathrm{m}$

$d_{\text {surf }} \quad$ Critical thickness of surface-water film, m

$\Delta H \quad$ Enthalpy change, $\mathrm{J} \mathrm{kg}^{-1}$

$h \quad$ Heat transfer coefficient, $\mathrm{W} \mathrm{m}^{2} \mathrm{~K}^{-1}$

$K \quad$ Apparent transfer coefficient, $\mathrm{m}^{2} \mathrm{~s}^{-1}$

$k \quad$ Thermal conductivity, $\mathrm{W} \mathrm{m}^{-1} \mathrm{~K}^{-1}$

$L \quad$ Latent heat of water vaporization under atmospheric pressure, $\mathrm{J} \mathrm{kg}^{-1}$

$l \quad$ Length, $\mathrm{m}$

$M \quad$ Weight of coal or water (in simulation), $\mathrm{kg}$

$\Delta Q \quad$ Heat transfer, $\mathbf{J}$

$R \quad$ Radius of the sample, $\mathrm{m}$

$r \quad$ Outer radius of the layer, $\mathrm{m}$

$r_{\mathrm{wd}} \quad$ Critical radius of a water droplet attached to the surface of lignite, $\mathrm{m}$

$T$ Temperature, $\mathrm{K}$

$t$ Time, seconds or minutes or hours (shown in each Figure)

$t_{\text {comp }}$ Time to complete superheated steam drying, $\mathrm{s}$

$\Delta t \quad$ Time step, seconds

$V \quad$ Volume, $\mathrm{m}^{3}$

$W \quad$ Weight (in experiments), $\mathrm{g}$

$X \quad$ Moisture content, dimensionless $\left(\mathrm{kg}-\mathrm{H}_{2} \mathrm{O} / \mathrm{kg}\right.$ dry coal)

$X_{\text {eq }} \quad$ Equilibrium moisture content, dimensionless (kg- $\mathrm{H}_{2} \mathrm{O} / \mathrm{kg}$-dry coal)

\section{GREEK SYMBOLS}
$\rho \quad$ Density, $\mathrm{kg} \mathrm{m}^{-3}$
$\varphi$ Volume fraction, dimensionless

\section{SUBSCRIPTS}

ave Average throughout the drying process

c Coal (dry coal)

center Center of a lignite particle

CDRP Constant drying rate period

cond Condensation

evap Evaporation of water

ex Exuded water

ini Initial

midpoint Midpoint between the center and the surface of a lignite particle

$n$

$\mathrm{s}$

surf Water on the surface

surface Surface of a lignite particle

trans Transfer of water

w Water

\section{REFERENCES}

1. A.W. Clarke and J.A. Trinnaman: 2010 Survey of Energy Resources, World Energy Council, UK, 2010.

2. S.V. Jangam, M. Karthikeyan, and A.S. Mujumdar: Dry. Technol., 2011, vol. 29, pp. 395-407.

3. O. Hoehne, S. Lechner, M. Schreber, and H.J. Krautz: Dry. Technol., 2010, vol. 28, pp. 5-18.

4. D. Stokie, M.W. Woo, and S. Battacharya: Energy Fuels, 2013, vol. 27 , pp. $6598-6606$

5. A. Tahmasebi, J. Yu, Y. Han, H. Zhao, and S. Battacharya: AsiaPac. J. Chem. Eng., 2013, vol. 8, pp. 793-803.

6. D. Jeon, T. Kang, H. Kim, S. Lee, and S. Kim: Science China, 2011, vol. 7, pp. 1680-83.

7. H.S. Kim, Y. Matsushita, M. Oomori, T. Harada, J. Miyawaki, S.H. Yoon, and I. Mochida: Fuel, 2013, vol. 105, pp. 415-24.

8. K. Zhang and C. You: Energy Fuels, 2010, vol. 24, pp. 6428 36.

9. A.Y. Looi, K. Golonka, and M. Rhodes: Chem. Eng. J., 2002, vol. 87 , pp. $329-38$

10. T. Kiriyama, H. Sasaki, A. Hashimoto, S. Kaneko, and M. Maeda: Mater. Trans. JIM, 2013, vol. 54, pp. 1725-34.

11. Y. Fei, A.A. Aziz, S. Nasir, W.R. Jackson, M. Marshall, J. Hulston, and A.L. Chaffee: Fuel, 2009, vol. 88, pp. 1650-55.

12. R. Toei, M. Okazaki, M. Kimura, and K. Kubota: Chem. Eng. Jpn, 1966, vol. 30, pp. 949-50.

13. D.J. Allardice, L.M. Clemow, G. Favas, W.R. Jackson, M. Marshall, and R. Sakurovs: Fuel, 2003, vol. 82, pp. 661-67.

14. Y. Fei, A.L. Chafee, M. Marshall, and W.R. Jackson: Fuel, 2005, vol. 84 , pp. $1557-62$.

15. D.J. Allardice and D.G. Evans: Fuel, 1971, vol. 50, pp. 201-10.

16. R.B. Bird, W.E. Stewart, and E.N. Lightfoot: Transport Phenomena, 2nd ed., John Wiley \& Sons, New York, 2006, pp. 764 804.

17. L.A. Richards: J. Appl. Phys., 1931, vol. 1, pp. 318-33.

18. T. Inoue, H. Iyota, N. Nishimura, and T. Nomura: Trans. Jpn. Soc. Mech. Eng. B, 2007, vol. 73, pp. 1068-76.

19. J. Ewers, H.J. Klutz, W. Renzenbrink, and G. Scheffknecht: $V G B$ PowerTech, 2003, vol. 11, pp. 60-65.

20. H.J. Klutz, C. Moser, and D. Block: VGB PowerTech, 2006, vol. 11 , pp. 2-6.

21. W. Wagner and A. Pruß: J. Phys. Chem. Ref. Data, 2002, vol. 31, pp. 387-535.

22. JSME Data Book: Thermophysical Properties of Fluids, The Japan Society of Mechanical Engineers, Tokyo, 1983. 